Revista Universo Contábil, ISSN 1809-3337
Blumenau, v. 14, n. 2, p. 137-161, abr./jun., 2018
doi:10.4270/ruc.2018215
Disponível em www.furb.br/universocontabil

\title{
AVALIAÇÃO DA SUSTENTABILIDADE DA PRODUÇÃO SUINÍCOLA SOB O ENFOQUE DAS EXTERNALIDADES ${ }^{1}$
}

\section{PRODUCTION SUSTAINABILITY ASSESSMENT PIG UNDER THE FOCUS OF EXTERNALITIES}

\section{EVALUACIÓN DE LA SOSTENIBILIDAD DE LA PRODUCCIÓN SUINÍCOLA BAJO EL ENFOQUE DE LAS EXTERNALIDADES}

\author{
Silvana Dalmutt Kruger \\ Doutora em Contabilidade pela Universidade de Santa Catarina \\ Professora do Departamento de Ciências Contábeis da Universidade da Região de Chapecó \\ Endereço: Servidão Anjo da Guarda, 295-D, Efapi \\ CEP: 89809-900 - Chapecó - Brasil \\ E-mail: silvanak@unochapeco.edu.br \\ Telefone: (49) 3321-8000 \\ Sérgio Murilo Petri \\ Doutor em Engenharia de Produção pela Universidade Federal de Santa Catarina \\ Professor do PPG em Contabilidade da Universidade Federal de Santa Catarina \\ Endereço: Centro Socioeconômico (Bloco F) - Campus Universitário - Trindade \\ CEP: 88040-970 - Florianópolis - SC - Brasil \\ E-mail: smpetri@gmail.com \\ Telefone: (48) 3721-6608
}

\section{RESUMO}

O estudo tem por objetivo estabelecer um conjunto de indicadores e métricas para avaliação da sustentabilidade da produção suinícola, visando à evidenciação das externalidades positivas e negativas da atividade. Utiliza-se da Técnica Delphi como procedimento metodológico de apoio para o desenvolvimento da pesquisa, as etapas de operacionalização foram: (i) Identificação inicial de indicadores de sustentabilidade por meio da literatura; (ii) Realização de entrevistas junto aos especialistas e posterior aplicação de questionário, visando identificar parâmetros legais e aceitáveis para as métricas dos indicadores de desempenho ambiental, social e econômico-financeiro; (iii) A partir das métricas ordinais (níveis superiores e inferiores), identificam-se as escalas cardinais por meio das funções de valores lineares, permitindo identificar as taxas de compensação e a valoração do conjunto de indicadores ambientais, sociais e econômico-financeiros; (iv) Aplicação do constructo de indicadores e métricas,

1 Artigo recebido em 28/02/2018. Revisado por pares em 04/09/2018. Reformulado em 05/12/2018. Recomendado para publicação em 05/12/2018 por Franciele Beck. Publicado em 20/02/2019. Organização responsável pelo periódico: FURB. 
denominado Sistema de Gestão e Avaliação da Sustentabilidade da Suinocultura - SIGEASS, junto a uma entidade rural.. O SIGEASS é composto por um conjunto 10 indicadores e 60 métricas de avaliação da sustentabilidade. O resultado do teste de aderência do SIGEASS evidenciou externalidades negativas nos indicadores ambientais de avaliação do solo e energia. Os indicadores ar/efeito estufa e remuneração do capital investido apresentaram externalidades positivas, enquanto seis indicadores se apresentaram com avaliação de conformidade. A avaliação da sustentabilidade a partir do SIGEASS, evidencia as externalidades positivas e negativas da atividade suinícola, visando minimizar externalidades negativas em prol de melhores práticas de sustentabilidade.

Palavras-chave: Indicadores de sustentabilidade; Externalidades; Produção suinícola; Avaliação de desempenho.

\section{ABSTRACT}

The objective of this study is to establish a set of indicators and metrics for assessing the sustainability of pig production, aiming to highlight the positive and negative externalities of the activity. Methodologically the research is characterized as qualitative of phenomenological character. The Delphi Technique is used as a methodological support method for the development of the research. The operational stages were: (i) Initial identification of sustainability indicators through literature; (ii) Conducting interviews with the specialists and then applying a questionnaire to identify legal and acceptable parameters for the metrics of environmental, social and economic-financial performance indicators; (iii) From ordinal metrics (upper and lower levels), the cardinal scales are identified through the functions of linear values, allowing the identification of compensation rates and the valuation of the set of environmental, social and economic-financial indicators; (iv) Application of the indicators and metrics construct, called Swine Sustainability Management and Evaluation System - SIGEASS, with a rural entity. SIGEASS is composed of a set of 10 indicators and 60 metrics for evaluating sustainability. The results of the SIGEASS adherence test revealed negative externalities in the soil and energy environmental indicators. The indicators air / greenhouse effect and remuneration of invested capital presented positive externalities, while six indicators presented themselves with conformity assessment. The sustainability assessment based on SIGEASS shows the positive and negative externalities of the swine activity, aiming at minimizing negative externalities in favor of better sustainability practices.

Palavras-chave: Sustainability indicators; Externalities; Pig production; Performance evaluation.

\section{RESUMEN}

El estudio tiene por objetivo establecer un conjunto de indicadores y métricas para la evaluación de la sostenibilidad de la producción porcina, visando la evidencia de las externalidades positivas y negativas de la actividad. Metodológicamente la investigación se caracteriza como cualitativa de carácter fenomenológico. Se utiliza de la Técnica Delphi como procedimiento metodológico de apoyo para el desarrollo de la investigación, las etapas de operacionalización fueron: (i) Identificación inicial de indicadores de sustentabilidad a través de la literatura; (ii) Realización de entrevistas a los especialistas y posterior aplicación de cuestionario, buscando identificar parámetros legales y aceptables para las métricas de los indicadores de desempeño ambiental, social y económico-financiero; (iii) A partir de las métricas ordinarias (niveles superiores e inferiores), se identifican las escalas cardinales por medio de las funciones de valores lineales, permitiendo identificar las tasas de compensación y la valoración del conjunto de indicadores ambientales, sociales y económico-financieros; (iv) Aplicación del constructo de indicadores y métricas, denominado Sistema de Gestión y Evaluación de la Sostenibilidad 
de la Suinocultura - SIGEASS, junto a una entidad rural. El SIGEASS está compuesto por un conjunto de 10 indicadores y 60 métricas de evaluación de la sostenibilidad. Los resultados de la prueba de adherencia del SIGEASS evidenció externalidades negativas en los indicadores ambientales de suelo y energía. Los indicadores aire / efecto invernadero y remuneración del capital invertido presentaron externalidades positivas, mientras que seis indicadores se presentaron con evaluación de conformidad. La evaluación de la sostenibilidad a partir del SIGEASS, evidencia las externalidades positivas y negativas de la actividad porcina, con el objetivo de minimizar externalidades negativas en favor de mejores prácticas de sostenibilidad.

Palabras clave: Indicadores de sostenibilidad; externalidades; Producción porcina; Evaluación del desempeño.

\section{INTRODUÇÃO}

As proposições de Pigou (1920) sustentam a preocupação com os efeitos da poluição relacionadas ao processo de produção e ao consumo, bem como seus reflexos nos bens públicos. Estes problemas são externalidades, as quais podem ultrapassar limites e fronteiras nacionais, causando efeitos intergeracionais (NORDHAUS, 1991; FARZIN, 1996; JOHN; PECCHENINO, 1997; ESHET; AYALON; SHECHTER, 2005; VAN DE BERG, 2010; BAIARDI; MENEGATTI, 2011; MASOUDI; ZACCOUR, 2013).

A noção de externalidade transmite a ideia de que as interações humanas, ou as interdependências dos processos de produção se estendem para além dos mercados formais, caracterizados pelos preços e pelo consumo. Neste sentido, a presença de uma externalidade significa que alguém está dependente de fatores que não estão sob sua responsabilidade ou controle (vítima), mas estes são decididos por outros seres humanos ou organizações (poluidores) (ESHET; AYALON, 2005; KAPLOW, 2012). Conceitualmente as externalidades já remetem a possível conexão com a sustentabilidade, sendo uma expressão do pensamento sistêmico, enfatizando o caráter dinâmico e contextual do ambiente econômico combinado com os reflexos ambientais e sociais (VAN DE BERGH, 2010).

As externalidades ambientais causam efeitos tangíveis e intangíveis. Para aqueles cujos impactos se estendem por um longo período, as alterações no meio ambiente podem implicar irreversibilidades, e esta seria uma forma extrema de incapacidade de substituição dos recursos naturais. Além disso, um evento irreversível é sofrido pelas próximas gerações e por todas as gerações seguintes (SAEZ; REQUENA, 2007). Neste sentido, destaca-se a importância de estudos e o desenvolvimento de novas ferramentas para a avaliação das externalidades ambientais.

Para atender a condição de desenvolvimento sustentável é necessário um período suficientemente longo para cobrir os interesses das gerações futuras. Impactos ambientais e externalidades ambientais inibem as perspectivas sustentáveis, logo, externalidade é um conceito-chave para a sustentabilidade. O problema da insustentabilidade está relacionado principalmente aos impactos ambientais que podem afetar o bem-estar e o potencial de bemestar das futuras gerações e dos indivíduos em distantes localizações geográficas. Dessa forma, os impactos ambientais causam externalidades ambientais e têm dimensões físicas extensas no tempo e no espaço, e neste aspecto torna-se relevante realizar pesquisas que busquem propor critérios éticos para lidar com as inevitáveis externalidades (BITHAS, 2011).

No campo das pesquisas acerca da sustentabilidade, e no caso específico da agricultura e os diversos aspectos da sustentabilidade, estudos como os de Tanzil e Bellof (2006); Hardi e Zdan (1997); Pintér et al. (2012), propõem alternativas para a análise das práticas rurais. Se algo não pode ser medido, é improvável que possa ser melhorado (DEMING, 1966). Nesta perspectiva os indicadores devem ser vistos como a lente para a análise da sustentabilidade. No contexto dos sistemas rurais de produção, devem ser considerados o tipo de cultura ou atividade, 
o ambiente socioeconômico, o clima e o solo, como fatores essenciais para se estabelecer limiares ou níveis de referência para avaliar a sustentabilidade dos sistemas agrícolas (SANTIAGO-BROWN et al., 2015).

Para garantir a sustentabilidade das atividades desenvolvidas no meio rural, a exemplo de qualquer outra atividade ou exploração, devem ser considerados três aspectos: econômicos, ambientais e sociais. Para uma atividade ser considerada como sustentável, visando não comprometer os recursos das gerações futuras e agregar benefícios para a sociedade (ANGLADE, 1999), deve atender simultaneamente a três requisitos: (i) economicamente viável; (ii) ecologicamente saudável; e (iii) socialmente equitativa. O conceito reconhecido pelo equilíbrio entre as três variáveis, denominado Triple Bottom Line, preconiza o equilíbrio entre o desempenho econômico-financeiro, ambiental e social (HENRIQUES; RICHARDSON, 2004; FIGGE; HAHN, 2004; ELKINGTON, 2012).

Em relação ao desenvolvimento da produção suinícola no Brasil, destaca-se sua relevância econômica e social, seja na geração de empregos e/ou renda para o meio rural, além de agregar valor à cadeia produtiva como um todo, no entanto, devem ser considerados os aspectos relacionados ao potencial poluidor da atividade suinícola, especialmente em relação à destinação adequada dos dejetos produzidos, ponderando que há falta de gestão ambiental e de evidenciação dos impactos e danos causados ao meio ambiente (MIELE; WAQUIL, 2007). Assim, medidas e indicadores são necessários, visando garantir por meio de medidas de avaliação contínua melhorias em prol do desenvolvimento sustentável. Neste aspecto, Melo e Cândido (2013) destacam a importância e a necessidade de estudos voltados à análise e avaliação da sustentabilidade das atividades desenvolvidas no meio rural, considerando que a exploração destas requer procedimentos que reflitam a preocupação para com o desenvolvimento sustentável.

A análise da produção suinícola evidencia que seu desenvolvimento gerou expressivos ganhos de produtividade e eficiência técnica, sendo um modelo concentrado em um menor número de produtores e em menor área geográfica, visando à geração de ganhos de escala e eficiência logística. Todavia, este modelo resulta em maiores danos ao meio ambiente e evidencia-se insustentável quando o volume de dejetos produzidos supera a capacidade do ambiente local em assimilar a produção, além da exclusão daqueles produtores de suínos menos competitivos (EMBRAPA, 2009; SPIES, 2009).

Neste contexto, diante das externalidades relacionadas à exploração da atividade suinícola, o estudo busca responder a seguinte questão-problema: Como a avaliação da sustentabilidade da produção suinícola, pode contribuir na evidenciação de externalidades positivas e negativas da atividade? Com o objetivo de estabelecer um conjunto de indicadores e métricas para avaliação da sustentabilidade da produção suinícola, visando à evidenciação das externalidades positivas e negativas da atividade.

Justifica-se a relevância do estudo considerando que os indivíduos, organizações e a sociedade precisam de modelos, métricas e ferramentas para avaliar as atividades produtivas, a fim de ajudar os decisores a se afastarem de práticas insustentáveis, além disso, o estabelecimento de medidas apropriadas e significativas é essencial para promover melhorias em prol da sustentabilidade, o que pode não ocorrer se não houver medição e comparação (SANTIAGO-BROWN et al., 2015).

A revisão da literatura acerca das avaliações baseadas em indicadores, mostra que nas discussões sobre avaliação da sustentabilidade de sistemas produtivos, o componente ambiental normalmente domina ou prevalece no contexto das análises, todavia, o foco apenas na sustentabilidade ambiental compromete a plena compreensão da importância da busca do equilíbrio entre os componentes ambientais, sociais e econômicos ao longo do tempo; relevando-se também como uma lacuna de pesquisa (SANTIAGO-BROWN et al., 2015). Entende-se que um conjunto de indicadores e métricas para avaliar a sustentabilidade deve 
considerar em seu desenvolvimento as dimensões econômica, ambiental e social, visando garantir além da avaliação, melhorias contínuas dos processos em prol da minimização das externalidades negativas relacionadas ao processo de produção rural, como a exemplo da produção suinícola.

Destaca-se a preocupação inicial da pesquisa com o uso de métricas para avaliar a sustentabilidade da atividade suinícola e possibilitar a análise de níveis de desempenho, como preconizam Melnyk et al., (2014) e Neely (1999), visando contribuir com a implementação da avaliação de desempenho da sustentabilidade como suporte ao processo de decisório, inclusive das entidades rurais. Estudos e pesquisas voltados ao contexto das atividades rurais, tornam-se relevantes para preencher uma lacuna teórica, especialmente em relação ao uso de indicadores de desempenho e da avaliação conjunta dos aspectos ambientais, sociais e econômicofinanceiros (SANTIAGO-BROWN et al., 2015). Neste sentido a preocupação de quantificar e estabelecer métricas de avaliação para os indicadores de sustentabilidade da produção suinícola, alinha-se as recomendações e iniciativas dos Princípios de Bellagio, para fomentar os processos de avaliação da sustentabilidade (HARDI; ZDAN, 1997).

\section{REVISÃO DA LITERATURA}

Nesta seção contempla-se a relação entre as externalidades, o desenvolvimento sustentável e a sustentabilidade, bem como a importância dos indicadores de avaliação da sustentabilidade.

\subsection{Externalidades e sua relação com o desenvolvimento sustentável e a sustentabilidade}

As proposições da Teoria das Externalidades sustentam a preocupação com os efeitos da poluição, relacionadas ao processo de produção e ao consumo, bem como seus efeitos no meio ambiente (JOSKOW, 1992). A regulação do uso dos bens públicos e as preocupações com as gerações futuras norteiam diversas pesquisas (JOHN; PECCHENINO, 1997; ESHET; AYALON; SHECHTER, 2005; VAN DE BERG, 2010; BAIARDI; MENEGATTI, 2011; MASOUDI; ZACCOUR, 2013), visando encontrar alternativas para minimizar e controlar as externalidades negativas dos processos produtivos.

A poluição gera custos sociais, os quais precisam ser confrontados com os resultados econômicos. As taxas e subsídios são alguns dos mecanismos que podem contribuir para equilibrar as necessidades e interesses de investimentos sociais (BAUMOL, 1972; ESHET; AYALON, 2005). Os efeitos das externalidades ambientais são intertemporais e podem levar a insustentabilidade, porque as decisões atuais afetam futuras gerações (VAN DE BERG, 2010). Não considerar as gerações futuras nas decisões atuais, estabelece externalidades intergeracionais peculiares e distintivas, sendo que os potenciais de bem-estar das gerações futuras são possivelmente afetados sem compensação. Tais preocupações têm sido reconhecidas pelos economistas neoclássicos e ecológicos.

Neste aspecto, a preservação das funções ambientais, dos serviços e da infraestrutura é uma solução para as externalidades ambientais negativas, sendo possível de ser concebida em termos ambientais, mas não pode ser expressa apenas por meio de avaliações econômicas. Desse modo, é preciso definir metas em termos biológicos-ecológicos, visando preservar os direitos ambientais das futuras gerações e minimizar as externalidades negativas em detrimento da sustentabilidade (BITHAS, 2011).

A primeira referência acerca do conceito de desenvolvimento sustentável é encontrada no Relatório Brundtland, que é resultado do encontro da Comissão Mundial sobre Meio Ambiente e Desenvolvimento, em 1987, criada pela Organização das Nações Unidas (ONU). O conceito oriundo do Relatório Brundtland (1987) é um marco na discussão deste tema por 
considerar o desenvolvimento sustentável como a capacidade de atender as necessidades do presente, sem comprometer as gerações futuras (MARZALL; ALMEIDA, 2000).

O Relatório Brundtland definiu o desenvolvimento sustentável como "o desenvolvimento que satisfaz as necessidades do presente sem comprometer a capacidade das futuras gerações para atender suas próprias necessidades” (WCED, 1987, p. 43). Tal definição reflete a consideração simultânea acerca de três importantes aspectos: a) o reconhecimento da limitação dos recursos naturais; b) a aceitação da necessidade de equidade entre as gerações; e c) questões sociais e espaciais resumidas como equidade intrageneracional (REIG-MARTÍNEZ; GÓMEZ-LIMÓN; PICAZO-TADEO, 2011).

Outro marco sobre desenvolvimento sustentável, oriundo das discussões e propostas da II Conferência Mundial sobre o Meio Ambiente e Desenvolvimento (1992), enfatizou a necessidade do desenvolvimento de indicadores para a sustentabilidade, que devem ser elaborados por cada país a partir das suas realidades distintas, mas com o intuito de evidenciar as preocupações com o desenvolvimento sustentável (MARZALL; ALMEIDA, 2000).

As discussões acerca do conceito de desenvolvimento sustentável trouxeram mudanças nas relações entre a humanidade e a natureza, questionando a visão capitalista de crescimento e agregando a preocupação com o conhecimento humano e a necessidade de novas tecnologias (VAN BELLEN, 2005). Parris e Kates (2003) evidenciam que a definição de desenvolvimento sustentável converge e inclui a satisfação das necessidades humanas, mas também se volta ao compromisso de reduzir a fome e a pobreza, além de garantir a preservação dos recursos naturais e sistemas de suporte para a continuidade da vida.

O desenvolvimento sustentável reconhece que a erradicação da pobreza em todas as suas formas e dimensões, o combate às desigualdades dentro dos e entre os países, a preservação do planeta, a criação do crescimento econômico sustentado, inclusivo e sustentável e a promoção da inclusão social estão vinculados uns aos outros e são interdependentes (OECD, 2003).

A sustentabilidade pode ser definida como uma filosofia, um conjunto de estratégias, a capacidade de cumprir uma série de metas, ou a capacidade de continuar fazendo melhorias ao longo do tempo sob condições variáveis, comumente se refere a práticas que são ambientalmente corretas, economicamente rentáveis e socialmente justas, no entanto, como estas práticas são definidas e equilibradas refletem prioridades e, portanto, podem mudar com o tempo e as circunstâncias vivenciadas pela sociedade (HANSEN, 1996).

O conceito de desenvolvimento sustentável é composto de um conjunto de capitais: (i) capital feito pelo homem (tais como bens produzidos); (ii) capital humano (como conhecimentos e habilidades); (iii) capital natural (recursos naturais); e (iv) capital social (relações com os indivíduos), esse conjunto de capitais pode ser chamado de desenvolvimento sustentável, desde que haja a garantia de consistência ao longo do tempo entre essas variáveis. Neste sentido, surgem as medidas de avaliação, com o objetivo de avaliar as práticas e ações das organizações voltadas à contribuição para com o meio ambiente e a sociedade, compreendendo simultaneamente as três dimensões de análise: ambiental, social e econômica (FIGGE; HAHN, 2004).

Veleva e Ellenbecker (2001) apresentam seis aspectos principais que constituem o desenvolvimento de práticas de produção sustentável: (i) energia e uso de materiais/recursos; (ii) ambiente/recursos naturais; (iii) justiça social e desenvolvimento comunitário; (iv) desempenho econômico; (v) trabalhadores; e (vi) produtos. Tais aspectos, devem ser observados pelas empresas que desejam embasar suas práticas cotidianas e evidenciar a adoção de medidas em prol do desenvolvimento sustentável.

Como acontece com outros conceitos como a democracia, o socialismo e o meio ambiente, o conceito de sustentabilidade tem significados diferentes, a definição citada frequentemente remete ao Relatório de Bruntland (1987), o qual procurou conciliar as reivindicações concorrentes de desenvolvimento econômico com a conservação do recursos 
naturais, enfatizando a necessidade de legar às futuras gerações recursos ambientais, tais preocupações remetem a necessidade de monitoramento de informações para medir o progresso e as práticas sustentáveis (HUGHES, 2002).

Rigby et al. (2001) destacam que o conceito de desenvolvimento sustentável possui mais de 386 definições distintas, significa coisas diferentes para indivíduos distintos, neste sentido relaciona a interpretação e compreensão da sustentabilidade, ao conceito de democracia, evidenciando que embora ocorram diferentes interpretações e abordagens, e que difere quando observado a partir de pessoas ou lugares e culturas diferentes, o conceito de sustentabilidade difere entre os indivíduos, do espaço e do tempo.

Devido à complexidade e a falta de consenso em torno do conceito de sustentabilidade, muitas abordagens diferentes têm sido feitas para avaliar a sustentabilidade, no entanto muitos pesquisadores se detém a adoção de práticas de conservação dos recursos naturais, e a sustentabilidade ambiental se tornou o componente mais importante de muitas das avaliações propostas, todavia, as avaliações que consideram apenas uma ou duas das categorias do triple bottom line são insuficientes para avaliar completamente a sustentabilidade, considerando-a como um conceito de abordagem sistêmica que deve ponderar componentes sociais, ambientais e econômicos concomitantemente (SANTIAGO-BROWN et al., 2015). A compreensão da sustentabilidade preconiza o equilíbrio entre os aspectos das dimensões ambiental, social e econômico-financeira (BRUNTLAND, 1987; VELEVA; ELLENBECKER, 2001; KOLK; MAUSER, 2002; PARRIS; KATES, 2003; HENRIQUES; RICHARDSON, 2004; FIGGE; HAHN, 2004), e remete à necessidade da análise e mensuração de indicadores de desempenho, visando possibilitar a avaliação da sustentabilidade, inclusive para as atividades desenvolvidas no meio rural (DALE et al., 2012).

Uma das definições de sustentabilidade para o contex to rural, considera a capacidade do sistema manter sua produtividade à longo prazo (CONWAY, 1987). Um sistema é considerado sustentável se atender aos seguintes critérios: (i) melhoria e manutenção da fertilidade do solo e produtividade; (ii) satisfação das necessidades humanas; (iii) viabilidade econômica das atividades; (iv) aceitabilidade social; (v) adaptação ecológica; (vi) durabilidade a longo prazo deste sistema (GASPAR et al., 2009; GÓMEZ-LIMÓN, 2010 ).

Corroborando, Melo e Cândido (2013, p. 1) enfatizam a "necessidade urgente da realização de estudos e pesquisas que considerem os aspectos da sustentabilidade das atividades agrícolas, tendo a agricultura como uma base fundamental para o desenvolvimento sustentável". Para apoiar eficazmente a tomada de decisão, indicadores e métricas devem estar ligados a objetivos-chave de uma organização e integrar importantes aspectos que precisam ser gerenciados em prol do desenvolvimento sustentável (TANZIL; BELOFF, 2006).

Neste sentido, Santiago-Brown et al. (2015), destacam que desde a consciência de sustentabilidade a partir de 1980, diversos métodos de avaliação têm sido propostos, no entanto, a maioria das avaliações estão voltadas aos componentes do meio ambiente ou sob o enfoque econômico, poucos são os estudos focados na avaliação da sustentabilidade (considerando os elementos sociais, econômicos e ambientais), para as explorações agrícolas de forma individual.

A avaliação da agricultura, especialmente nos países em desenvolvimento, terá de abordar de forma abrangente a sustentabilidade, a fim de evitar carências alimentares e a degradação ambiental, o que indica a necessidade de avaliação e de indicadores para o desenvolvimento de políticas e planos em prol de bases sustentáveis para a exploração dos recursos naturais (VAN PHAM; SMITH, 2014). Impactos ecológicos das atividades rurais incluem as emissões de gases de efeito de estufa, perda de biodiversidade, poluição generalizada por fertilizantes e pesticidas, degradação do solo, redução de polinizadores, e os riscos para a saúde humana, entre muitos outros (DELONGE; MILES; CARLISLE, 2016).

Entre as atividades rurais, destaca-se a produção suinícola no Brasil, sua relevância econômica e social, na geração de empregos e/ou renda para o meio rural. No entanto, aspectos 
relacionados ao potencial poluidor da atividade suinícola, especialmente em relação à destinação adequada dos dejetos produzidos, falta de gestão ambiental e de evidenciação dos impactos e danos causados ao meio ambiente, são preocupações inerentes à atividade (MIELE; WAQUIL, 2007; SPIES, 2009).

Contribuindo com a discussão conceitual acerca da sustentabilidade, Parris e Kates (2003) indicam que caracterizar e medir a sustentabilidade envolve fazer escolhas sobre como definir e quantificar o que se pretende avaliar e por quanto tempo, , portanto, o conceito de desenvolvimento sustentável tem amplo apelo político, criando-se um ambiente que é particularmente maduro para os grupos de defesa do meio ambiente e de causas sociais. No entanto, questiona-se acerca da efetividade das medidas e de avanços efetivos em prol do desenvolvimento sustentável.

\subsection{Importância dos indicadores de sustentabilidade}

Os indicadores de sustentabilidade devem proporcionar a compreensão do conceito de desenvolvimento sustentável. Tal compreensão pode se dar a partir da transformação do conceito em medidas operacionais, que devem promover a evidenciação das condições atuais para as tomadas de decisões no processo de desenvolvimento sustentável. A legitimidade (aceitação pela comunidade) é elemento importante na construção de medidas e indicadores, para que possam ser efetivos e subsidiarem o processo decisório, bem como os processos de avaliação complementares, as iniciativas que podem ser implementadas a partir do conjunto de indicadores e o progresso em relação ao cumprimento das metas estabelecidas (DAHL, 1997; HARDI; BARG; HODGE, 1997).

Os termos indicadores e métricas são muitas vezes utilizados alternadamente ao referirse as medidas de sustentabilidade. Contudo, o termo indicadores é usado de modo mais amplo, englobando tanto medidas quantitativas quanto as descrições operatórias de questões de aspectos fundamentais que precisam ser gerenciados. Por outro lado, o termo métricas é usado quase que exclusivamente ao referir-se aos aspectos quantitativos ou aos índices que permitem as medições qualitativas ou quantitativas (TANZIL; BELOFF, 2006).

Para a definição de indicadores de sustentabilidade deve-se entendê-los como medidas quantitativas, porém dotadas de significados qualitativos, que permitem analisar e acompanhar: (i) o passado, o estado atual e as tendências culturais, sociais, econômicas e ambientais de curto, médio ou longo prazo; (ii) os níveis de satisfação social em relação as práticas, ações ou políticas implementadas; (iii) a relevância do contexto local, regional, nacional ou internacional das medidas; (iv) o caráter do indicador quanto aos seus objetivos: problemas (pressões/estado), ou soluções (respostas), metas, meios ou resultados (JANNUZZI, 2001).

A necessidade do desenvolvimento de indicadores de desempenho que contribuem com medidas para promover melhorias nas práticas empresariais, bem como, para evidenciar as iniciativas de cada país e seu conjunto de empresas em prol do desenvolvimento sustentável, implicou no surgimento de diversas propostas e indicadores para a avaliação do desenvolvimento sustentável. Os indicadores representam a informação utilizada para medir e motivar o progresso em direção às metas de produção sustentáveis definidas pelos acordos internacionais entre as nações (VELEVA; ELLENBECKER, 2001).

O uso de medidas para avaliar o desempenho permite a identificação de níveis de desempenho, bem como a comparação entre os níveis desejados e a adaptação de estratégias para atingir os objetivos ao longo do caminho (MELNYK et al., 2014). Neely (1999) contribui com este argumento evidenciando a necessidade de intervenção e esforços que possam gerar benefícios e a implementação e medidas de desempenho, como suporte ao processo de decisório.

A adoção de práticas agrícolas mais sustentáveis implica na definição de indicadores de sustentabilidade, que se deslocam em direção aos sistemas agrícolas, oferecendo incentivos ou 
impondo regulamentos para orientar o comportamento do agricultor (WEINBERG; KLING, 1996). Neste sentido, indicadores quantitativos são apropriados para avaliar as condições atuais e alertar para os problemas inerentes ao contexto da exploração rural. O desafio é desenvolver um conjunto de indicadores que sejam facilmente mensuráveis e relacionados com as condições socioeconômicas e ambientais com escalas apropriadas para a gestão rural, incluindo aspectos do clima, biodiversidade, produtividade, solo, água, qualidade do ar e a eficiência do uso dos recursos (DALE et al., 2013). Além de contemplar aspectos relacionados ao capital humano, como a mão de obra, capacitação, saúde, participação social, e os aspectos econômicofinanceiros como os recursos e o investimento realizado (FIGGE; HAHN, 2004; BITHAS, 2011).

\section{PROCEDIMENTOS METODOLÓGICOS}

A forma de coleta de dados e os procedimentos de análise foram constituídos a partir da Técnica Delphi, utilizada como instrumento de apoio a coleta de medidas, visando à identificação e qualificação de um constructo de indicadores e métricas a partir das perspectivas dos especialistas.

Dalkey e Helmer (1963) salientam que o método Delphi se utiliza de três características básicas: (i) questionamento repetido dos indivíduos/especialistas; (ii) evita o confronto direto dos especialistas, mas o faz de forma indireta, controlada e anônima por meio do método; (iii) permite conhecer as opiniões dos especialistas. O uso da técnica Delphi é recomendado nas situações em que determinado problema observado pode se beneficiar de julgamentos subjetivos, e que os indivíduos ou especialistas não têm histórico de se comunicarem, neste sentido, a heterogeneidade dos participantes deve ser preservada (especialistas com formações e experiências diferentes), visando a garantia da validade dos resultados (LINSTONE; TUROFF, 2011). Delphi.

Apresenta-se na Figura 1 as etapas que compõem a metodologia de análise da Técnica

Figura 1 - Etapas do desenvolvimento e aplicação da Técnica Delphi no roteiro da pesquisa

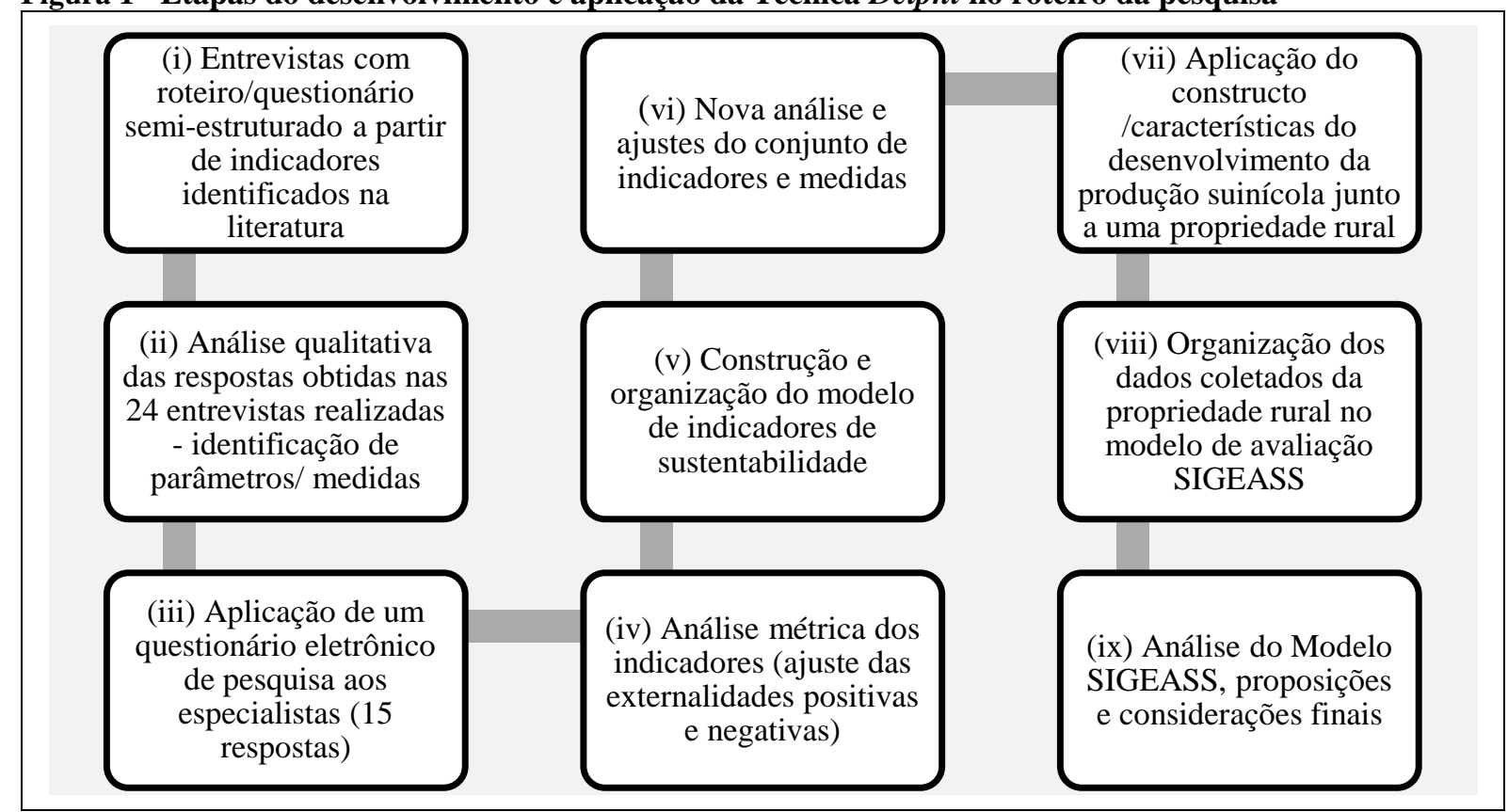

Fonte: Elaborada pelos autores. 
Pode-se observar na Figura 1 que a pesquisa inicia com a identificação de indicadores e medidas por meio da literatura e posteriormente a técnica Delphi foi usada para abordar as três questões principais junto aos especialistas, inicialmente por meio de entrevistas individuais:

1. Em que medida os indicadores de desempenho ambiental, social e econômicofinanceiro permitem avaliar as práticas do desenvolvimento da produção suinícola, qual seria o parâmetro limitador (diferenciar o mínimo aceitável, e o ideal ou recomendável)?

2. Quais dos indicadores ou critérios de avaliação se sobrepõem a outros (entre o conjunto de indicadores apresentados), qual seria o conjunto ideal de indicadores para avaliar a sustentabilidade da produção suinícola?

3. Quais outros critérios ou características deveriam ser implementadas visando avaliar a sustentabilidade da produção suinícola, pensando num sistema de avaliação contínua?

No Quadro 1 destaca-se a categoria dos profissionais que contribuíram com a construção das métricas de avaliação e na identificação de métricas superiores e inferiores de desempenho para cada indicador da análise, considerando as duas rodadas da técnica Delphi.

Quadro 1: Construto conceitual da avaliação de desempenho
\begin{tabular}{|l|l|c|c|}
\hline $\begin{array}{c}\text { Categoria dos } \\
\text { profissionais } \\
\text { especialistas }\end{array}$ & \multicolumn{1}{|c|}{ Experiência/ Currículo dos especialistas } & $\begin{array}{c}\mathbf{1}^{\mathbf{a}} \text { Rodada } \\
\text { Delphi - } \\
\text { entrevistas }\end{array}$ & $\begin{array}{c}\mathbf{2}^{\mathbf{a}} \text { Rodada } \\
\text { Delphi - } \\
\text { questionários }\end{array}$ \\
\hline Técnicos & $\begin{array}{l}\text { Profissionais que atuam na avaliação e desempenho das } \\
\text { práticas da produção suinícola, vinculados a Empresa } \\
\text { Brasileira de Pesquisa Agropecuária -EMBRAPA e a } \\
\text { Secretaria de Agricultura do Estado de Santa Catarina } \\
\text { (Profissionais com doutorado) }\end{array}$ & 19 & 10 \\
\hline Gerenciais & $\begin{array}{l}\text { Profissionais que conhecem o contexto da produção } \\
\text { suinícola e atuam nas etapas de análise do processo } \\
\text { produtivo (profissionais com atuação em empresas). }\end{array}$ & 2 & 2 \\
\hline Científicos & $\begin{array}{l}\text { Profissionais que conhecem aspectos legais e normativos, } \\
\text { especialmente quanto à avaliação ambiental, social e } \\
\text { econômico-financeira (Profissionais com experiência } \\
\text { acadêmica de pesquisa, com doutorado). }\end{array}$ & 3 & 3 \\
\hline
\end{tabular}

Fonte: Elaborado pela autora.

Os especialistas são classificados em 3 categorias (técnicos, gerenciais e científicos), visando agregar o conhecimento e as experiências acerca da construção dos indicadores e métricas, no intuito de qualificar o constructo final a ser proposto para a avaliação da sustentabilidade contemplando o desempenho econômico-financeiro, ambiental e social.

Após as entrevistas iniciais e da identificação das métricas de desempenho para os indicadores, realizadas junto aos especialistas, adequou-se um questionário eletrônico ponderando sobre as métricas de avaliação da sustentabilidade, o mesmo foi enviado de forma eletrônica aos especialistas, visando identificar novas ponderações ou observações por parte destes sobre o conjunto de indicadores adequados após as entrevistas.

Destaca-se que as entrevistas realizadas com os especialistas tiveram como documento norteador (conforme o exemplo do Apêndice A, quanto aos critérios ambientais), uma relação de indicadores identificados na literatura. Todavia, identificou-se uma lacuna em relação as métricas de avaliação, ponderando critérios que possibilitassem a avaliação da sustentabilidade. Neste sentido, identificou-se com os especialistas as medidas e critérios para avaliação do conjunto de indicadores. A técnica Delphi é um procedimento sistemático para a coleta de opinião de especialistas sobre determinado assunto, permitindo sua validade científica pelos procedimentos utilizados. Sua estratégia não é identificar um consenso ou convergência, mas permitir a identificação das diversas possibilidades, ou maior gama destas, para a resolução de um mesmo problema (DALKEY; HELMER, 1963). 
A partir da identificação das métricas superiores e inferiores de desempenho para cada indicador da análise e da análise dos especialistas, identificou-se as escalas ordinais, conforme a teoria da mensuração. As funções de valor e as escalas ordinais permitem a identificação de níveis neutro ou bom, permitindo a identificação dos indicadores das entidades neste contexto (ENSSLIN et al., 2010). Posteriormente a identificação das escalas ordinais, identificou-se as escalas cardinais e as funções lineares destes indicadores, ponderando os aspectos das discussões realizadas e as percepções do pesquisador frente às respostas dos especialistas. Porém, ainda identificaram-se indicadores com métricas de avaliação (superior e inferior), com unidades de avaliação em fatores, nestes casos estes tiveram evidenciadas as suas escalas com a indicação de características qualitativas.

Quanto as definições conceituais utilizadas no decorrer do processo de coleta e análise de resultados para a avaliação de desempenho da produção suinícola, destacam-se as delimitações de Melnyk et al. (2014), quanto à distinção entre as terminologias: medida, métrica, conjunto métrico, sistema de mensuração e avaliação de desempenho, conforme destacado no Quadro 1.

\section{Quadro 2: Constructo conceitual da avaliação de desempenho}

\begin{tabular}{|c|c|}
\hline $\begin{array}{l}\text { Definições } \\
\text { conceituais }\end{array}$ & Mensuração e avaliação de desempenho \\
\hline $\begin{array}{l}\text { Indicadores são } \\
\text { medidas de } \\
\text { desempenho }\end{array}$ & $\begin{array}{l}\text { Os indicadores representam medidas de desempenho, compreendidos nesta pesquisa como } \\
\text { a quantificação e representação das condições relacionadas aos aspectos ambientais, sociais } \\
\text { e econômico-financeiros da atividade suinícola, verificados a partir dos critérios } \\
\text { estabelecidos para a sua verificação. } \\
\text { Os indicadores podem ser compreendidos como os aspectos observados nas dimensões } \\
\text { ambiental, social e econômico-financeira, visando contribuir com a avaliação do } \\
\text { desempenho. No modelo apresentado os indicadores são apresentados com elementos de } \\
\text { avaliação e métricas de desempenho. }\end{array}$ \\
\hline Métricas & $\begin{array}{l}\text { As métricas (ou também denominadas por vezes parâmetros) representam simultaneamente } \\
\text { as três características dos indicadores, nestes aspectos: } \\
\text { (i) Identificação da uma medida de desempenho que quantifica o que está acontecendo; } \\
\text { (ii) Identificação de um padrão de desempenho, que indica o que é considerado como } \\
\text { recomendável ou o mínimo aceitável no desempenho da produção suinícola; } \\
\text { (iii) Identificação de externalidades negativas ou positivas por estar abaixo ou acima do } \\
\text { padrão de desempenho desejado. } \\
\text { As métricas são identificadas para cada indicador, permitindo a análise dos critérios mínimos } \\
\text { aceitáveis, e os critérios desejáveis, conforme a avaliação realizada pelos especialistas. As } \\
\text { métricas possibilitam identificar a condição atual e possibilidades de melhoria no } \\
\text { desempenho. }\end{array}$ \\
\hline $\begin{array}{l}\text { Conjunto de } \\
\text { indicadores - } \\
\text { Constructo }\end{array}$ & $\begin{array}{l}\text { A representação de um conjunto de medidas e métricas, permitem a avaliação da } \\
\text { sustentabilidade da produção suinícola a partir deste construto, o qual pretende servir de } \\
\text { orientação para processos de melhorias contínuas na gestão das propriedades rurais que } \\
\text { desenvolvem a atividade. } \\
\text { O conjunto de indicadores de desempenho ambiental, social e econômico-financeiro permite } \\
\text { avaliar a sustentabilidade da produção suinícola por meio das externalidades observadas. }\end{array}$ \\
\hline $\begin{array}{l}\text { Sistema de } \\
\text { Mensuração e } \\
\text { Avaliação de } \\
\text { Desempenho }\end{array}$ & $\begin{array}{l}\text { Um sistema de avaliação de desempenho abrange processos desde o desenvolvimento do } \\
\text { conjunto de medidas e métricas para a mensuração dos dados de desempenho, até o } \\
\text { gerenciamento dos resultados. O objetivo do Sistema de Gestão e Avaliação da } \\
\text { Sustentabilidade da Suinocultura -SIGEASS é avaliar o desempenho da produção suinícola } \\
\text { a partir de um conjunto de indicadores, evidenciando as externalidades positivas e negativas } \\
\text { da atividade. }\end{array}$ \\
\hline
\end{tabular}

Fonte: Elaborado pelos autores a partir dos conceitos de Melnyk et al. (2014).

As definições conceituais apresentadas no Quadro 2 norteiam o processo de coleta e análise dos resultados, quanto as características para a identificação de indicadores de desempenho que permitam avaliar os aspectos ambientais, sociais e econômico-financeiros da produção suinícola, a partir de métricas que possam representar um sistema de avaliação da 
sustentabilidade da produção suinícola. Com este enfoque, o estudo propõe o Sistema de Gestão e Avaliação da Sustentabilidade da Suinocultura- SIGEASS, como instrumento de identificação e análise de parâmetros de aceitabilidade para o desenvolvimento da produção suinícola.

Para operacionalizar o Constructo SIGEASS os pesquisadores atribuíram pesos percentuais proporcionais ao conjunto de indicadores das dimensões ambiental $(33,33 \%)$, social $(33,33 \%)$ e econômico-financeira $(33,33 \%)$, e cada elemento de avaliação e suas métricas também receberam pesos percentuais proporcionais a quantidade de métricas de cada conjunto. No Quadro 4, no teste de aderência do Modelo SIGEASS pode-se observar os percentuais utilizados e as medidas proporcionais atribuídas para cada indicador de avaliação.

O Quadro 3 destaca a identificação dos conceitos utilizados a partir da teoria da mensuração, conforme Ensslin et al. (2010), para a construção do Constructo de indicadores e métricas de avaliação da sustentabilidade.

Quadro 3: Critérios utilizados para avaliar os indicadores de desempenho

\section{Critérios para avaliar os indicadores de desempenho}

\begin{tabular}{|l|l|}
\hline $\begin{array}{l}\text { Taxas de compensação } \\
\text { (função linear) }\end{array}$ & $\begin{array}{l}\text { Indicam a condição geral de atendimento ao constructo, considerado 100\% para } \\
\text { casos que atendam a todas as indicações/ou métricas identificadas como medidas } \\
\text { superiores. As taxas de compensação somam 100\% para cada aspecto da } \\
\text { avaliação (ambiental, social e econômico-financeiro). }\end{array}$ \\
\hline Unidade & Unidade indicativa da análise (se em \%, R\$, fatores, metros, m³, etc.). \\
\hline $\begin{array}{l}\text { Medidas Superior } \\
\text { (ordinal) }\end{array}$ & Maior nível - sugerido como ideal, ou condição favorável para a atividade. \\
\hline Medidas Inferior (ordinal) & $\begin{array}{l}\text { Menor nível sugerido, ou condição mínima para a atividade, abaixo desta condição } \\
\text { evidenciam-se externalidades negativas. }\end{array}$ \\
\hline Pontuação Superior & 100 pontos \\
\hline Pontuação Inferior & 0 pontos \\
\hline Medida (cardinal) & $\begin{array}{l}\text { Identificação da condição da entidade rural, a partir de suas condições ambientais, } \\
\text { sociais e econômico-financeiras. Identificada a partir do Roteiro estruturado e das } \\
\text { métricas de avaliação identificados no Constructo SIGEASS. }\end{array}$ \\
\hline Pontuação pela escala de & $\begin{array}{l}\text { Reflete a condição das medidas em relação as taxas de compensação de cada } \\
\text { conjunto de indicadores, evidenciando a valoração das externalidades positivas ou } \\
\text { negativas da atividade. }\end{array}$ \\
\hline
\end{tabular}

Fonte: Elaborado pelo autor.

Após a identificação das taxas de compensação para avaliar os indicadores de desempenho, das medidas superiores e inferiores (identificadas com os especialistas), para validar a proposta SIGEASS, realizou-se o teste de aderência do constructo SIGEASS junto a uma entidade rural, conforme evidenciado na Figura 1 acerca das etapas da técnica Delphi. A aplicação do SIGEASS permitiu analisar: (i) indicadores e métricas; (ii) capacidade de mudança em direção a metas sustentáveis (externalidades positivas); (iii) aos investimentos e sua relação com indicadores sociais e ambientais; (iv) etapas e aprendizagem para a avaliação e melhorias contínuas aos processos de produção.

Para a coleta de dados a aplicação do SIGEASS em outras entidades rurais, como Constructo para a Avaliação da Sustentabilidade, apresenta-se no Apêndice B um roteiro estruturado para a coleta de dados, visando identificar as práticas produtivas para posterior avaliação em relação as métricas de desempenho e a análise das externalidades positivas e negativas da atividade suinícola.

\section{ANÁLISE E INTERPRETAÇÃO DOS RESULTADOS}

Apresenta-se nesta seção o conjunto de indicadores e os critérios observados para a identificação de métricas sob o enfoque ambiental, social e econômico-financeiro, bem como as justificativas encontradas para os critérios de análise e mensuração dos indicadores, visando 
destacar as métricas superiores e inferiores das práticas desenvolvidas no contexto da produção suinícola.

A coleta de dados e aplicação do constructo junto à propriedade rural A, localizada no Município de Quilombo-SC, possibilitou observar e identificar as características do desenvolvimento da produção suinícola, bem como analisar os indicadores propostos para a avaliação da sustentabilidade da produção suinícola. A propriedade rural possui 28 hectares, 3 integrantes da família atuam no desenvolvimento da produção suinícola, não utilizam mão de obra de terceiros. O sistema de produção é o de Unidade de Produção de Leitões (UPL), desenvolvido em parceria com uma Cooperativa da região oeste catarinense. A quantidade média de matrizes alojadas é 350 unidades, e o média de leitões desmamados/entregues é de 700 por mês. A entidade utiliza esterqueira como sistema de tratamento dos dejetos da atividade.

Observa-se na análise do Quadro 4, o conjunto de elementos de avaliação compostos pelos indicadores de desempenho ambiental e o constructo de medidas de avaliação. A partir dos indicadores e sua descrição, identificou-se as unidades e dos critérios ordinais para cada indicador. Pode-se observar as métricas superiores ou inferiores (parâmetros identificados com especialistas), e a pontuação (superior e inferior), permitindo a obtenção da pontuação específica da entidade rural, obtida a partir da coleta de dados realizada.

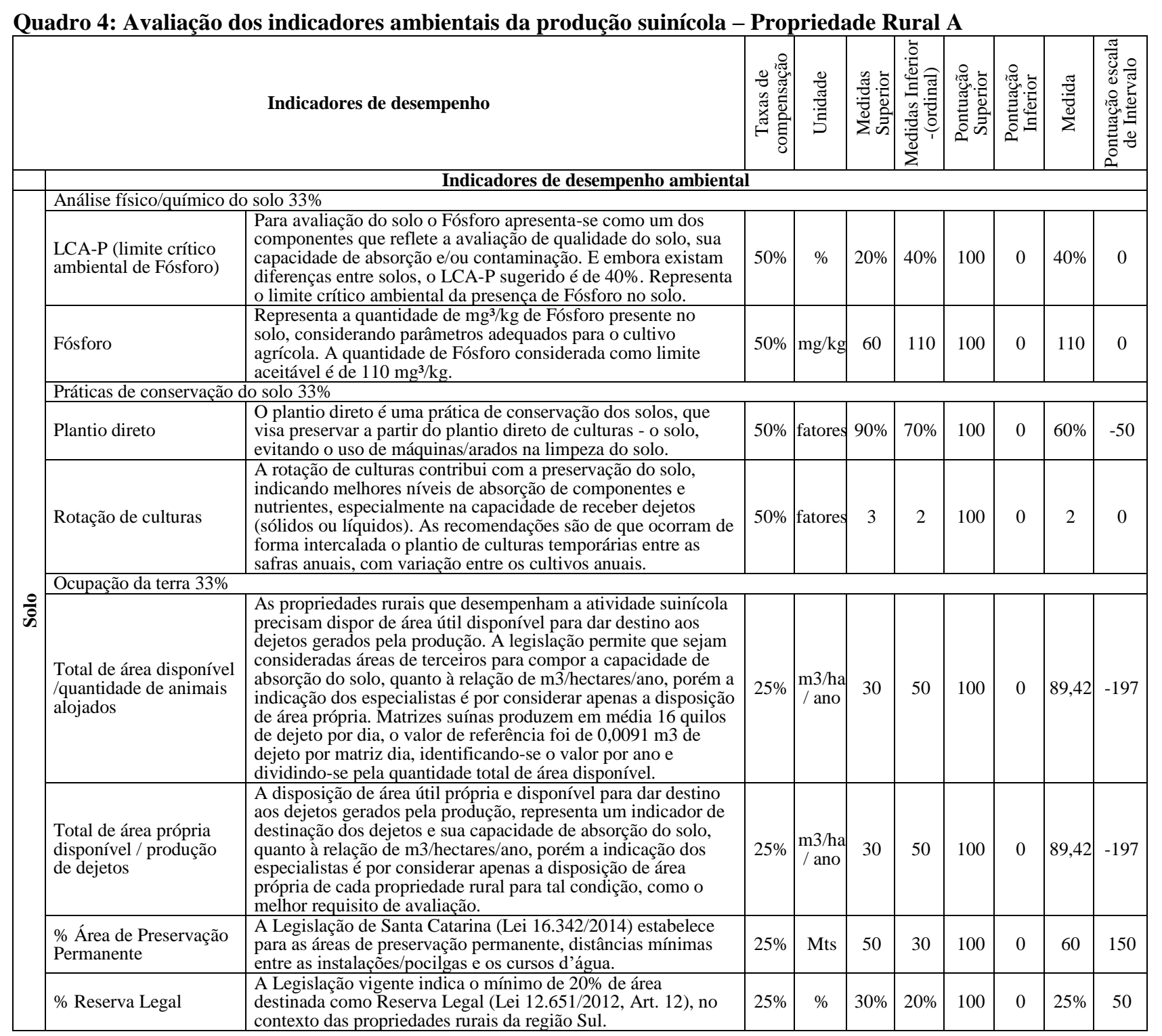




\section{AVALIAÇÃO DA SUSTENTABILIDADE DA PRODUÇÃO SUINÍCOLA SOB O ENFOQUE DAS EXTERNALIDADES}

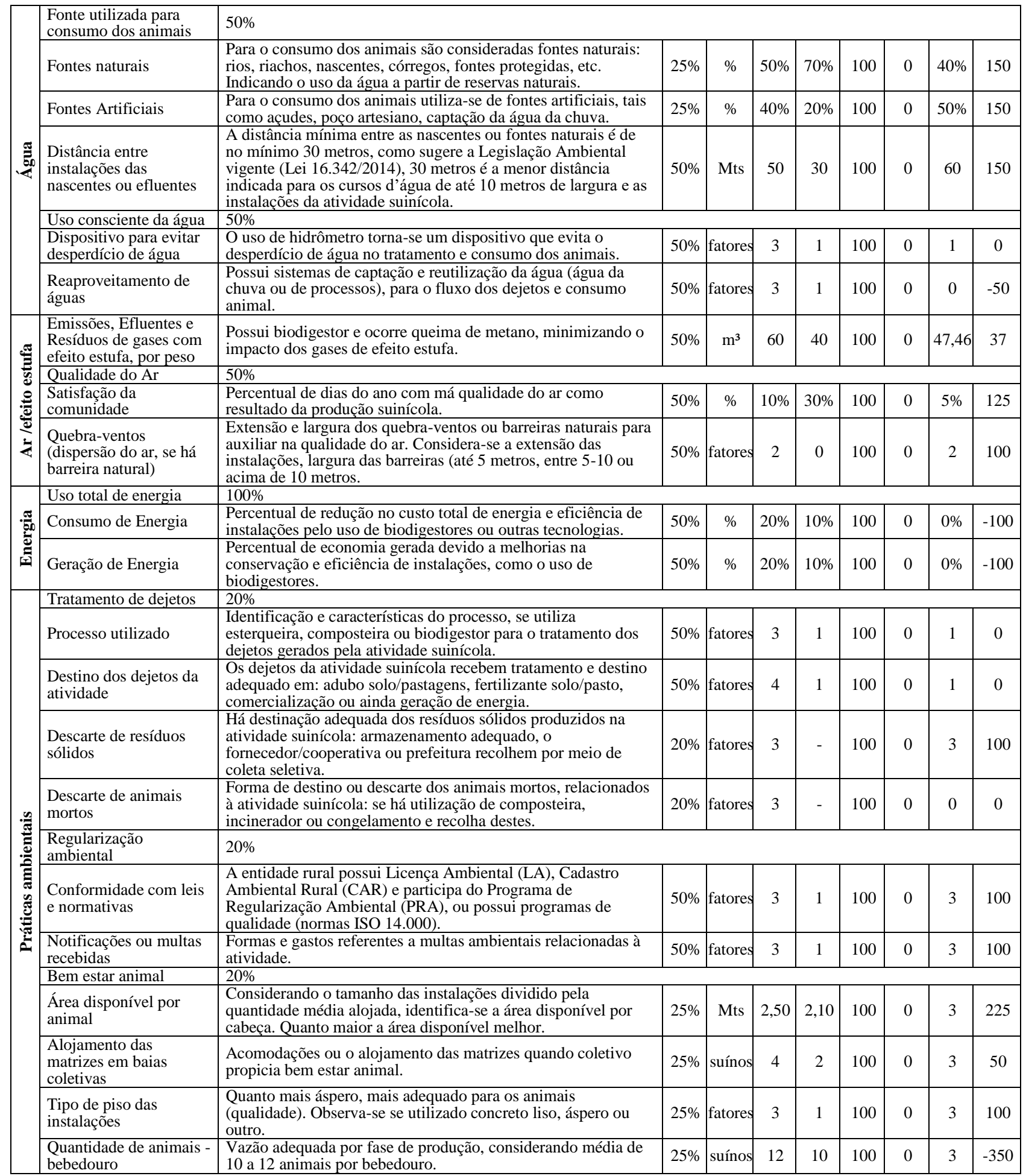

Fonte: Elaborado pelos autores com dados da pesquisa.

Para a composição das métricas de avaliação, utilizou-se as unidades de valor, em anos, fatores, percentual, metros, m3/ha/ano, índices, grupos, pessoas, etc., visando expressar as métricas de avaliação utilizadas para representar cada indicador do modelo, conforme indicações dos especialistas. As taxas de compensação em contrapartida representam a somatória do conjunto de indicadores e seus elementos de avaliação no desempenho ambiental, e posteriormente no contexto social e econômico-financeiro.

Observa-se que diversas melhorias podem ser agregadas nesta entidade rural (pontuação "zero" por exemplo), tendo em vista que representam critérios que direta ou indiretamente 
afetam o meio ambiente. A rotação de culturas, torna-se um fator de conversação do solo, e especialmente na condição desta entidade representa uma prática necessária, diante da relação limitadora da área disponível com a quantidade de dejetos gerada. Neste sentido, o tratamento dos dejetos, embora legalmente autorizado por meio de licença ambiental e regulado pela entidade Cooperativa (como expresso pelo indicador de regularização ambiental), apresenta-se como um dos principais gargalos da produção suinícola, pois constatou-se que os gestores rurais utilizam esterqueiras para este processo, no entanto não ocorre a adequada decomposição dos dejetos, pois não há controle do tempo recomendado para posterior destinação. A retirada ocorre em média a cada 30 dias, conforme à quantidade acumulada e o destino é diretamente no solo.

Em relação ao descarte de animais mortos, não há um processo de recolha, o produtor rural indicou que não possui um local regular para a destinação ou decomposição destes. Quanto aos resíduos sólidos, a entidade Cooperativa faz a recolha destas embalagens e recipientes a cada seis meses (coleta seletiva). Outros aspectos de melhoria estão relacionados ao bem estar animal, como a área disponível de instalações e a quantidade de animais alojados, bem como a quantidade de bebedouros por animal, e embora utilize de baias coletivas no processo inicial de gestação, na fase final as matrizes são alojadas em baias individuais.

Os resultados de forma geral complementam as ponderações de Franco, Gaspar e Mesias (2012), ao avaliar a sustentabilidade na exploração de atividades rurais, chamando a atenção para medidas ou indicadores que somam atributos, de forma que no geral compensam pontuações baixas sobre outros aspectos deficitários, como a eficiência produtiva em relação ao uso sustentável de recursos naturais. Neste sentido, a análise dos indicadores e suas métricas permite observar possibilidades de melhoria e externalidades negativas a serem corrigidas.

No Quadro 5 apresenta-se os indicadores de avaliação social, bem como o constructo de medidas de avaliação e os resultados obtidos na análise da propriedade rural A.

Quadro 5: Avaliação dos indicadores sociais da produção suinícola - Propriedade Rural A

\begin{tabular}{|c|c|c|c|c|c|c|c|c|c|c|}
\hline \multicolumn{3}{|r|}{ Indicadores de desempenho } & 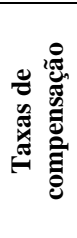 & 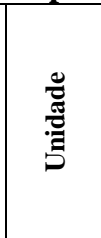 & 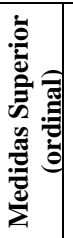 & 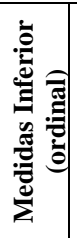 & 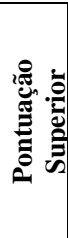 & 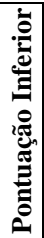 & 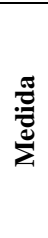 & 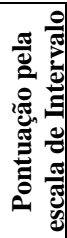 \\
\hline \multicolumn{11}{|c|}{ Indicadores de desempenho social } \\
\hline \multirow{9}{*}{ 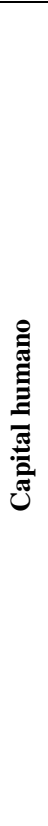 } & $\begin{array}{l}\text { Satisfação com o } \\
\text { meio rural }\end{array}$ & $\begin{array}{l}\text { Nota atribuída pela família acerca da satisfação em } \\
\text { viver no meio rural. }\end{array}$ & $20 \%$ & Nota & 9 & 7 & 100 & 0 & 8 & 50 \\
\hline & Sistema de trabalho & $20 \%$ & & & & & & & & \\
\hline & Mão de obra familiar & $\begin{array}{l}\text { A mão de obra utilizada na atividade suinícola é } \\
\text { familiar, e a receita desta garante-lhes remuneração. }\end{array}$ & $50 \%$ & pessoas & 4 & 2 & 100 & 0 & 3 & 50 \\
\hline & $\begin{array}{l}\text { Terceiros/ } \\
\text { colaboradores }\end{array}$ & $\begin{array}{l}\text { Se utiliza terceiros ou colaboradores estes são } \\
\text { registrados (regime de trabalho regular com carteira } \\
\text { de trabalho assinada, atende a CLT). }\end{array}$ & $50 \%$ & fatores & 3 & 1 & 100 & 0 & 3 & 100 \\
\hline & $\begin{array}{l}\text { Capacitação e } \\
\text { desenvolvimento de } \\
\text { pessoas }\end{array}$ & $20 \%$ & & & & & & & & \\
\hline & Capacidade técnica & $\begin{array}{l}\text { Quantidade de horas de capacitação anual voltada à } \\
\text { gestão do negócio ou da atividade suinícola - por } \\
\text { integrante da atividade. }\end{array}$ & $50 \%$ & horas & 20 & 10 & 100 & 0 & 3 & -70 \\
\hline & $\begin{array}{l}\text { Desenvolvimento do } \\
\text { capital humano }\end{array}$ & $\begin{array}{l}\text { Considera-se a formação técnica ou superior dos } \\
\text { gestores ou dos filhos que atuam na atividade } \\
\text { relacionada ao negócio (agronomia, gestão rural, } \\
\text { etc.). }\end{array}$ & $50 \%$ & fatores & 3 & 1 & 100 & 0 & 3 & 100 \\
\hline & Saúde da família & $\begin{array}{l}\text { Saúde dos gestores, se ocorrem/ possuem } \\
\text { enfermidades que os afastam das atividades no } \\
\text { decorrer do ano. }\end{array}$ & $20 \%$ & fatores & 3 & 1 & 100 & 0 & 3 & 100 \\
\hline & Sucessão familiar & $\begin{array}{l}\text { A família discute sobre o processo de sucessão } \\
\text { familiar, possui filhos que colaboram nas atividades } \\
\text { e têm interesse na sucessão/ continuidade das } \\
\text { atividades. }\end{array}$ & $20 \%$ & fatores & 3 & 1 & 100 & 0 & 3 & 100 \\
\hline
\end{tabular}




\section{EXTERNALIDADES}

\begin{tabular}{|c|c|c|c|c|c|c|c|c|c|c|}
\hline \multirow{5}{*}{ 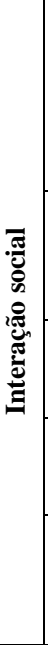 } & $\begin{array}{l}\text { Qualidade de vida na } \\
\text { comunidade }\end{array}$ & $\begin{array}{l}\text { Considera-se sua interação social como a } \\
\text { participação na comunidade (igreja, clube de mães, } \\
\text { serviços comunitários, etc), ou outros grupos na } \\
\text { comunidade. A interação social agrega valores de } \\
\text { convivência e facilita o bem estar da família na } \\
\text { comunidade. Quanto mais integrado melhor. }\end{array}$ & $20 \%$ & grupos & 3 & 1 & 100 & 0 & 3 & 100 \\
\hline & Participação social & $\begin{array}{l}\text { A participação em sindicatos profissional, rural, ou } \\
\text { em sociedades cooperativas são fatores de } \\
\text { esclarecimentos de dúvidas e de interação social, } \\
\text { representam fatores de interação social. }\end{array}$ & $20 \%$ & grupos & 3 & 1 & 100 & 0 & 3 & 100 \\
\hline & Programas sociais & $\begin{array}{l}\text { Participação dos gestores em programas, } \\
\text { capacitações, palestras e treinamentos para a } \\
\text { melhoria da qualidade de vida no meio rural. }\end{array}$ & $20 \%$ & horas & 15 & 5 & 100 & 0 & 10 & 50 \\
\hline & $\begin{array}{l}\text { Percepção de } \\
\text { impactos ambientais }\end{array}$ & $\begin{array}{l}\text { Percepção dos vizinhos, quanto aos impactos } \\
\text { ambientais da atividade suinícola (odor, dejetos, } \\
\text { etc.). }\end{array}$ & $20 \%$ & fatores & 3 & 1 & 100 & 0 & 3 & 100 \\
\hline & Fornecedores & $\begin{array}{l}\text { Considera a responsabilidade de fornecedores na } \\
\text { compra de insumos da atividade suinícola (fatores), } \\
\text { tais como a recolha de resíduos, a legalidade da mão } \\
\text { de obra, a instrução de uso, entre outros. }\end{array}$ & $20 \%$ & fatores & 3 & 1 & 100 & 0 & 3 & 100 \\
\hline \multirow{6}{*}{ 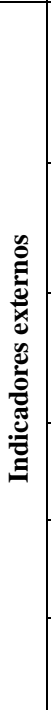 } & IDEB do Município & $\begin{array}{l}\text { O İndice de Desenvolvimento da Educação Básica } \\
\text { (IDEB), é medido por Município indicando } \\
\text { características de investimentos públicos com } \\
\text { educação e que refletem na qualidade do ensino ou } \\
\text { educação básica (IDEB - } 4^{\circ} \text { e } 5^{\circ} \text { ano). }\end{array}$ & $16,7 \%$ & fatores & 8 & 5 & 100 & 0 & 6,6 & 53 \\
\hline & $\begin{array}{l}\text { Índice de } \\
\text { desenvolvimento } \\
\text { municipal } \\
\text { sustentável } \\
\end{array}$ & $\begin{array}{l}\text { O IDMS desenvolvido pela FECAM permite } \\
\text { identificar características de desenvolvimento } \\
\text { sustentável, a partir dos investimentos realizados } \\
\text { pelos Municípios. }\end{array}$ & $16,7 \%$ & índice & 0,80 & 0,50 & 100 & 0 & 0,557 & 19 \\
\hline & Índice sociocultural & $\begin{array}{l}\text { O IS desenvolvido pela FECAM permite identificar } \\
\text { as características dos investimentos realizados pelos } \\
\text { Municípios em: educação, saúde, cultura e } \\
\text { habitação. }\end{array}$ & $16,7 \%$ & índice & 0,80 & 0,50 & 100 & 0 & 0,727 & 76 \\
\hline & Índice ambiental & $\begin{array}{l}\text { O IA desenvolvido pela FECAM permite identificar } \\
\text { as características dos investimentos realizados pelos } \\
\text { Municípios em ações ambientais. }\end{array}$ & $16,7 \%$ & índice & 0,80 & 0,50 & 100 & 0 & 0,264 & -79 \\
\hline & Índice econômico & $\begin{array}{l}\text { O IE desenvolvido pela FECAM permite identificar } \\
\text { as características dos investimentos econômicos } \\
\text { realizados pelos Municípios. }\end{array}$ & $16,7 \%$ & índice & 0,80 & 0,50 & 100 & 0 & 0,518 & 6 \\
\hline & $\begin{array}{l}\text { Índice político } \\
\text { institucional }\end{array}$ & $\begin{array}{l}\text { O IPI desenvolvido pela FECAM permite identificar } \\
\text { as características dos Municípios quanto a: finanças } \\
\text { públicas, gestão pública e participação social. }\end{array}$ & $16,7 \%$ & índice & 0,80 & 0,50 & 100 & 0 & 0,717 & 72 \\
\hline
\end{tabular}

Fonte: Elaborado pelos autores com dados da pesquisa.

O Quadro 5 destaca as características da entidade rural quanto aos aspectos sociais, os indicadores apresentados contemplam o capital humano (mão de obra familiar e capacitações para o desenvolvimento da atividade), a interação social (participação e integração na comunidade), e os indicadores externos como elementos de avaliação. Este conjunto de indicadores possui mais aspectos qualitativos, devido as características relacionadas ao capital humano e participação social, sendo variáveis pouco exploradas pela literatura de forma geral, quanto ao uso de métricas para sua avaliação.

No conjunto de indicadores externos, observa-se que o Índice Ambiental (FECAM, 2017), o Município de Quilombo-SC representa como medida 0,264, quando a média geral de Santa Catarina é de 0,480. A medida indica que o Município apresenta fragilidades em relação aos aspectos ambientais (saneamento básico, Agenda 21 e licenciamento de impacto local), com desempenho abaixo da média geral do Estado. Os índices da FECAM têm variação de 0,000 baixo a 1,0 alto. Neste sentido pode-se destacar que processos de coleta seletiva (resíduos sólidos e de animais), poderiam ser implementados por políticas públicas, inclusive quanto ao incentivo para a instalação de biodigestores, visando à redução do consumo de energia, e até mesmo para agregar geração de energia, mas especialmente, a redução de impactos ambientais no solo, na água e no ar, causados pelos dejetos da atividade suinícola. Estes investimentos agregariam melhores práticas nas entidades rurais e contribuiriam com a melhoria da evidenciação deste indicador ambiental. 
Nos aspectos observados de cunho social destaca-se a satisfação dos gestores com o meio rural (nota 8 de satisfação com o meio rural). Nesta entidade rural, o pai e dois filhos trabalham juntos no desenvolvimento da produção suinícola, e há o interesse de um dos filhos na continuidade do negócio. Há a participação da família na comunidade por meio de grupos sociais (igreja, grupo de jovens, cooperativa e sindicato), o que também contribui com a interação social da família e contribui na satisfação, como evidencia a nota geral atribuída pelo gestor em relação a satisfação destes com o meio rural. A recomendação principal do estudo se refere a capacitação dos gestores, visando o processo de melhorias contínuas em relação as práticas de gestão rural e da atividade suinícola, por meio de treinamentos, cursos e atividades com estas finalidades.

Já no Quadro 6 apresentam-se os indicadores econômico-financeiros, no contexto da entidade rural A.

Quadro 6: Avaliação dos indicadores econômico-financeiros da produção suinícola - Propriedade Rural A

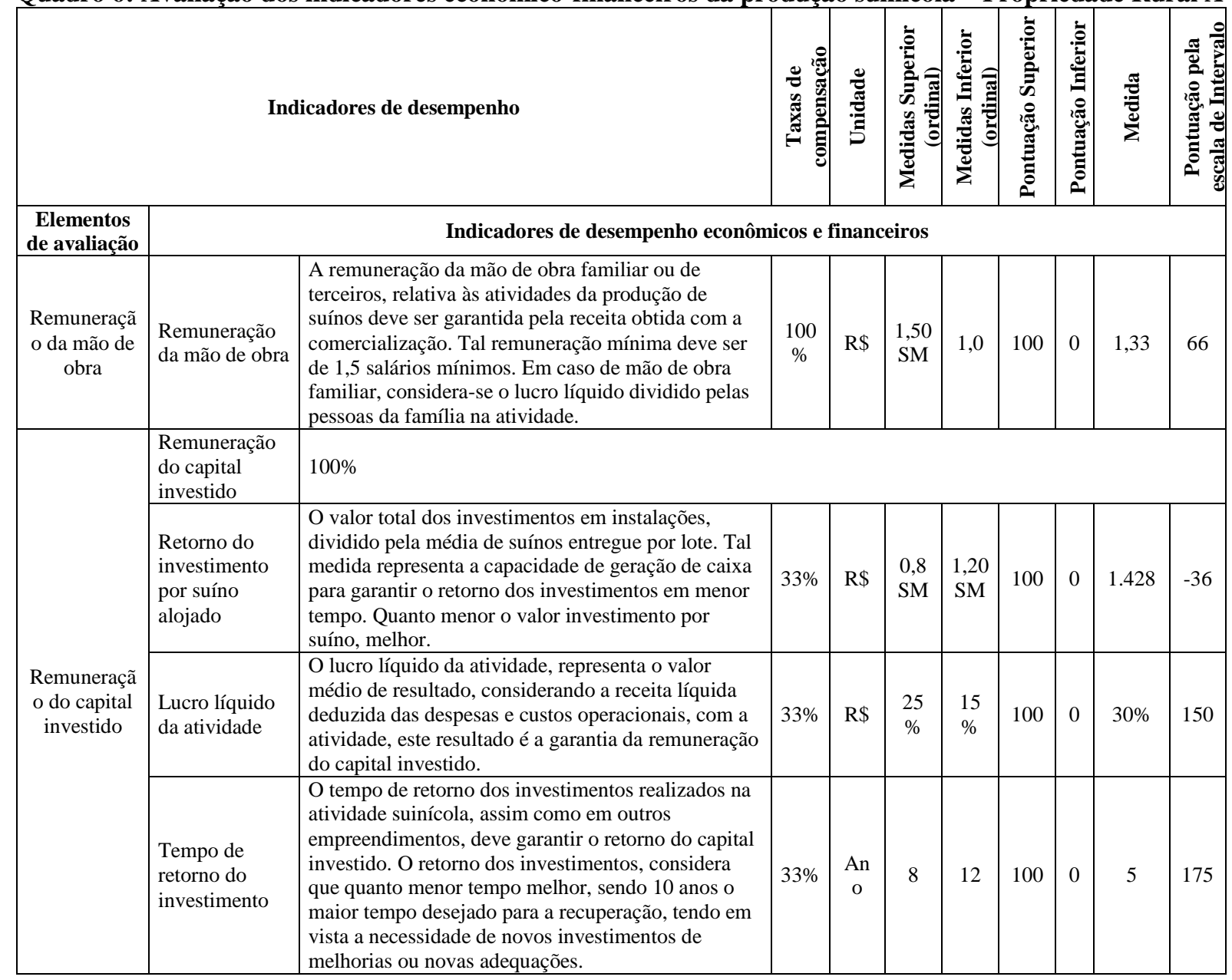

Fonte: Elaborado pelos autores com dados da pesquisa.

No Quadro 6, observa-se o conjunto de elementos de avaliação de desempenho econômico-financeiro e o constructo de medidas de avaliação, bem como a pontuação obtida pela análise realizada. Os elementos de avaliação consideram a remuneração da mão de obra e a remuneração do capital investido.

$\mathrm{Na}$ análise econômico-financeira observa-se que a atividade gera renda capaz de remunerar a família, também é capaz de agregar a recuperação do investimento realizado em menos de 8 anos. Os investimentos totalizaram cerca de $\mathrm{R} \$ 1.500 .000,00$ e o valor médio da receita mensal chega a $\mathrm{R} \$ 42.000,00$, deduzidos os gastos com energia elétrica, manutenções e 
mão de obra, o resultado medido pelo payback é que em aproximadamente 5 anos ocorre o retorno do capital investido.

A remuneração da mão de obra é fator principal da satisfação e permanência das famílias no meio rural, pois representa a compensação do esforço agregado, do trabalho realizado. Neste sentido percebeu-se as condições de vida (residências, organização da propriedade, conforto, veículo de passeio, etc.), refletem a capacidade da atividade suinícola remunerar a mão de obra da família e os investimentos realizados, e também relaciona-se com o indicador de satisfação da família com o viver no meio rural, tendo em vista que a renda ou sua remuneração reflete na segurança familiar e no bem estar.

Da análise desta propriedade rural, identificou-se concomitantemente nos Quadros 4, 5 e 6 os principais aspectos deficitários em relação ao conjunto de indicadores observados:

\begin{tabular}{|c|c|}
\hline \multicolumn{2}{|c|}{ Fragilidades e aspectos deficitários da produção suinícola } \\
\hline Plantio direto & $\begin{array}{l}\text { A prática de plantio direto é uma forma de conservação e preservação do solo, no entanto o produtor pela } \\
\text { necessidade de pastagens e troca de culturas, utiliza rotação de culturas, porém faz uso de técnica } \\
\text { mecanizada. }\end{array}$ \\
\hline $\begin{array}{l}\text { Total de área disponível } \\
\text { /quantidade de animais } \\
\text { alojados }\end{array}$ & $\begin{array}{l}\text { A relação de área disponível - em hectares, com a quantidade média de animais alojados, representa um } \\
\text { gargalo, tendo em vista a necessidade de destinação dos dejetos da atividade suinícola. }\end{array}$ \\
\hline $\begin{array}{l}\text { Total de área própria } \\
\text { disponível/produção de } \\
\text { dejetos }\end{array}$ & $\begin{array}{l}\text { A relação de produção de dejetos com a área própria disponível da propriedade rural, demonstra uma } \\
\text { fragilidade pois não possui área útil própria para destinar os dejetos gerados pela produção, o que } \\
\text { possivelmente representará excedente destes dejetos no solo. }\end{array}$ \\
\hline $\begin{array}{l}\text { Reaproveitamento de } \\
\text { águas }\end{array}$ & A entidade rural não utiliza, não possui nenhum sistema para auxiliar na captação de recursos hídricos. \\
\hline $\begin{array}{l}\text { Emissões, efluentes e } \\
\text { resíduos de gases com } \\
\text { efeito estufa }\end{array}$ & $\begin{array}{l}\text { A não utilização de sistemas de tratamento de dejetos eficientes, como composteira e biodigestor, é um } \\
\text { limitador das práticas ambientais nesta propriedade rural. }\end{array}$ \\
\hline Uso de Energia & $\begin{array}{l}\text { Observa-se que a entidade não possui sistema de geração e medidas para a redução do consumo, o que } \\
\text { poderia ser potencializado pelo uso de biodigestor. }\end{array}$ \\
\hline $\begin{array}{l}\text { Quantidade de animais } \\
\text { por bebedouro }\end{array}$ & $\begin{array}{l}\text { A média de animais por bebedouro na entidade rural encontra-se abaixo da recomendação obtida pelos } \\
\text { especialistas, indicando uma adequação a ser implementada na entidade rural. }\end{array}$ \\
\hline Capacidade técnica & $\begin{array}{l}\text { Observando as horas destinadas para qualificação e treinamentos, observa-se outra sugestão de melhoria, } \\
\text { visando agregar melhores práticas na gestão. Entende-se que a capacitação técnica representa inclusive fator } \\
\text { de melhoria contínua, e no longo prazo indiretamente agrega na satisfação com o meio rural (interação } \\
\text { social), e nos resultados econômico-financeiros obtidos. }\end{array}$ \\
\hline Índice ambiental & $\begin{array}{l}\text { Este indicador é resultado da avaliação dos investimentos públicos em relação ao meio ambiente (IA da } \\
\text { FECAM), representa que o município de Quilombo-SC, possui investimentos está abaixo da média } \\
\text { catarinense. Possivelmente boas práticas de coleta seletiva, por exemplo, que poderiam ser implementadas } \\
\text { pelo Poder Público Municipal não ocorrem. }\end{array}$ \\
\hline $\begin{array}{l}\text { Retorno do investimento } \\
\text { por suíno alojado }\end{array}$ & $\begin{array}{l}\text { Neste indicador observa-se a média entre o total de investimentos e a quantidade de animais alojados, quanto } \\
\text { maior a quantidade de animais, mais rápida a recuperação do valor investido. Embora nestas condições } \\
\text { atuais o retorno do investimento ocorre em até } 5 \text { anos. }\end{array}$ \\
\hline
\end{tabular}

Fonte: Elaborado pelos autores.

Observa-se no Quadro 7 aspectos deficitários e fragilidades que podem receber melhorias, visando a longo prazo minimizar as externalidades negativas da produção suinícola no ambiente de estudo. As externalidades ambientais negativas podem ser minimizadas por meio de adequadas técnicas de tratamento dos dejetos, como pelo uso de biodigestores. Já quando os resíduos gerados são excedentes, e não ocorre à reutilização ou reciclagem de todos os materiais produzidos, como no caso da relação entre área disponível e quantidade de dejetos gerados, o meio ambiente é afetado pelo excesso de dejetos (pode ainda comprometer recursos hídricos, o ar, gerar gases de efeito estufa). As externalidades negativas, estão relacionadas principalmente à poluição e a contaminação dos recursos naturais (CECHIN; VEIGA, 2010).

A partir do Modelo SIGEASS, pode-se avaliar os aspectos da produção suinícola, observando-se as externalidades negativas, as conformidades e as externalidades positivas, como evidenciado na Figura 2: 
Figura 1: Análise do Constructo SIGEASS - Aderência Propriedade Rural A

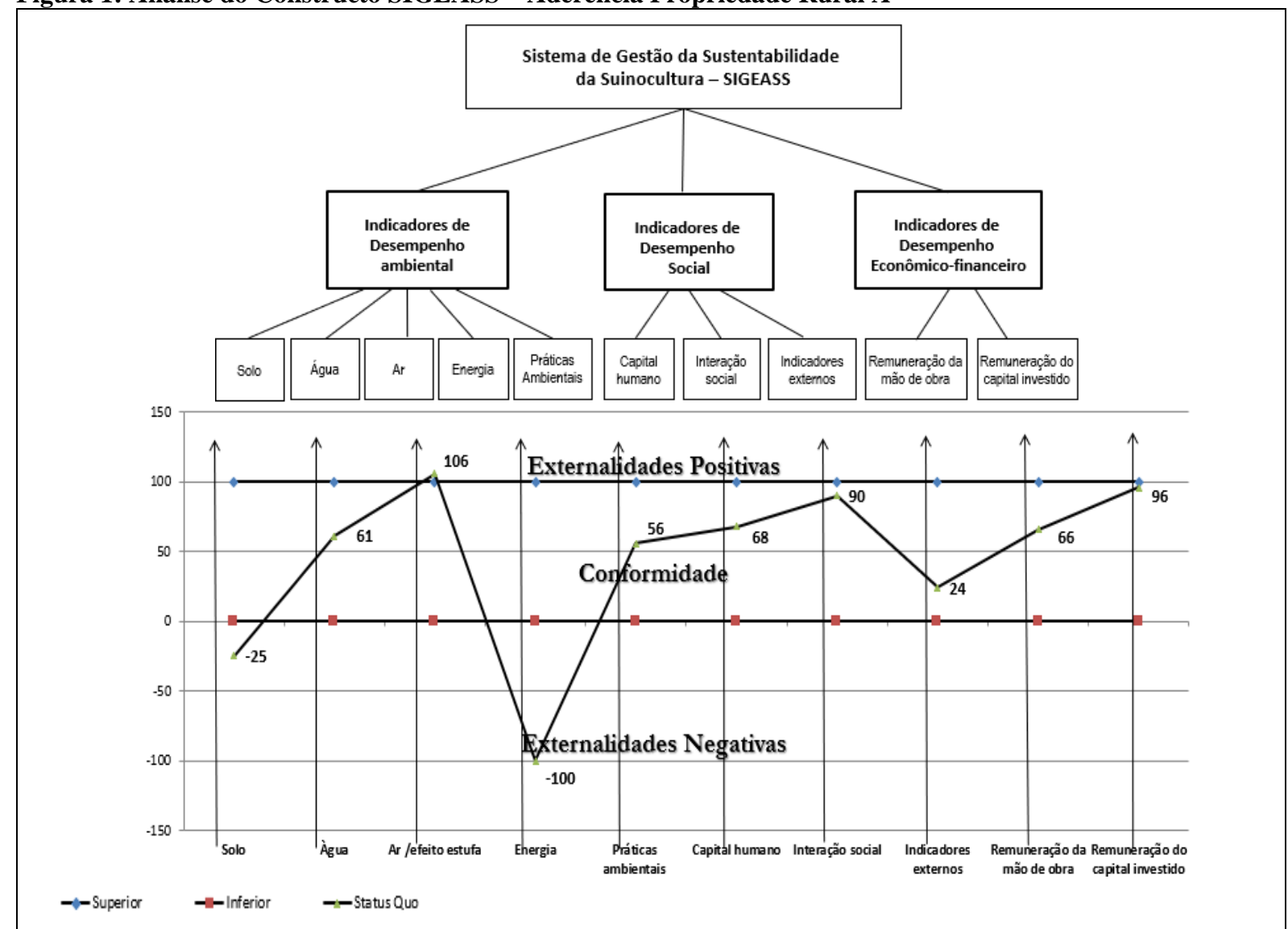

Fonte: Dados da pesquisa.

Os resultados apresentados na Figura 2 contemplam a análise realizada sob os aspectos ambientais, sociais e econômico-financeiros, visando demonstrar a avaliação da sustentabilidade da produção suinícola, desenvolvida na entidade rural objeto do estudo. Podese constatar na Figura 2 as ponderações observadas anteriormente, quanto as fragilidades do tratamento dos dejetos e a área própria disponível para tal destinação, demonstrando que as práticas ambientais relacionadas ao uso do solo representam externalidades negativas, bem como à falta de iniciativas para minimizar o consumo de energia, demonstradas como externalidades negativas da produção suinícola nesta entidade rural.

Quanto as externalidades positivas, pode-se observar que indicadores ambientais como ar/efeito estufa e a remuneração do capital investido atingem avaliação superior, enquanto outros indicadores como água, capital humano, interação social, remuneração da mão de obra tiveram avaliação

Os achados coadunam com a pesquisa de Santiago-Brown et al. (2015), destacando a relevância dos fatores econômico-financeiros, sociais e ambientais, para a avaliação da sustentabilidade, bem como, a utilização de variáveis nestes aspectos, que possam refletir as circunstâncias de cada indivíduo (gestor) e o contexto da produção que desenvolve (fazenda), permitindo a comparabilidade entre propriedades rurais e o apoio ao processo de gestão das atividades desenvolvidas. Os aspectos relacionados ao controle e a mensuração das externalidades devem considerar o equilíbrio da relação entre a produção, o consumo e o meio ambiente (BITHAS, 2011).

Os resultados da presente pesquisa corroboram com as recomendações propostas por Rigby et al. (2001), quanto a necessidade da mensuração de métricas de sustentabilidade a partir da realidade das práticas dos sistemas produtivos rurais, tendo em vista que as realidades produtivas são diferentes, e os dados coletados devem expressar as especificidades e permitir a 
avaliação comparativa como processo de melhoria contínua. Neste sentido, justifica-se a avaliação da suinocultura, como uma das atividades rurais de maior impacto no meio ambiente (MIELE; WAQUIL, 2007).

Dale et al. (2013), destaca que para medir a sustentabilidade dos sistemas produtivos agrícolas, e implementar medidas de desempenho para atividades produtivas, como no caso da produção suinícola, deve-se considerar a realidade social e permitir o acompanhamento contínuo, para auxiliar na melhoria das condições ambientais, sociais e econômicas. Destacase neste sentido as contribuições da pesquisa possibilitando a avaliação da sustentabilidade das atividades desenvolvidas no meio rural, como proposto por Melo e Cândido (2013) e SantiagoBrown et al., (2015), refletindo na preocupação para com o desenvolvimento sustentável.

De forma geral, a representação gráfica do Modelo SIGEASS contribui na evidenciação dos indicadores propostos para à análise, possibilitando observar tais indicadores em relação aos parâmetros adequados, ou seja, seu distanciamento em relação às externalidades positivas ou negativas. Destaca-se neste sentido o principal diferencial do estudo, para além da análise de indicadores de sustentabilidade, o SIGEASS distingue-se como um constructo de avaliação da sustentabilidade, possibilitando o controle e a mensuração das externalidades da atividade suinícola, no intuito efetivamente com o desenvolvimento sustentável da suinocultura.

Neste sentido, destaca-se a partir dos critérios observados a importância do conjunto de indicadores de sustentabilidade como mecanismo de avaliação, no intuito de agregar melhorias contínuas no desenvolvimento da produção suinícola. No constructo identifica-se a métrica superior e inferior, e com os dados de cada entidade rural, obtém-se o status quo do desempenho dos indicadores, destacando-se as externalidades positivas e negativas.

\section{CONSIDERAÇÕES FINAIS}

O presente estudo defende que por meio de um conjunto de indicadores ambientais, sociais e econômico-financeiros, pode-se avaliar a sustentabilidade da produção suinícola, visando evidenciar às externalidades positivas e negativas da atividade. Para atender ao objetivo proposto buscou-se a identificação de indicadores e métricas de desempenho da sustentabilidade, e a partir da análise de especialistas sobre o tema pesquisado, foi possível identificar um constructo para a avaliação da sustentabilidade da produção suinícola.

Buscar alternativas para minimizar as externalidades negativas das atividades rurais tornam-se mecanismos de apoio à gestão rural, visando a sustentabilidade das atividades produtivas, no intuito de agregar melhorias ao desenvolvimento e reduzir externalidades ambientais negativas. Ponderando que a gestão rural preocupa-se com o desempenho econômico-financeiro, os resultados da pesquisa revelam fragilidades nos aspectos sociais (requerem investimentos em políticas públicas de retenção e capacitação da mão de obra que vive no meio rural, visando maior interação social e valorização do meio rural, como mecanismo de garantir a sucessão familiar no meio rural), bem como nos aspectos ambientais, e embora devidamente regulamentadas por Licença Ambiental, as práticas desenvolvidas na produção suinícola geram externalidades negativas, que podem ser minimizadas por mudanças na forma de destinação dos dejetos da atividade.

O estudo apresenta um Modelo, denominado Sistema de Gestão e Avaliação da Sustentabilidade da Suinocultura - SIGEASS, contemplando uma proposta apresenta com métricas recomendáveis como critérios superiores, permitindo que a análise do conjunto de indicadores evidencie a partir da realidade de cada entidade rural sua condição em relação a sustentabilidade: (a) externalidades negativas; (b) conformidade; (c) externalidades positivas. Observando-se os resultados do Modelo SIGEASS, destaca-se também o papel da Ciência Contábil como instrumento de controle, registro, mensuração e evidenciação das informações apresentadas pelo Constructo, no intuito de agregar a avaliação comparativa ao longo do tempo, 
norteando o processo de gestão e tomada de decisão, em prol de investimentos e melhorias nas práticas produtivas, especialmente para a condição da atividade suinícola.

Destaca-se que o intuito da proposta é contribuir com a avaliação contínua da produção, ponderando-se a limitação da literatura sobre indicadores de desempenho para a atividade suinícola, e especialmente no contexto dos critérios de avaliação. Neste sentido o Modelo SIGEASS agrega a condição de analisar os indicadores por meio das métricas, que permitem avaliar os aspectos ambientais, sociais e econômico-financeiros, e observar os resultados por meio das condições das externalidades (se positivas ou negativas).

A aplicação do SIGEASS evidencia que as externalidades negativas da produção podem ser corrigidas, como por meio de adequações no tratamento dos dejetos, tendo em vista as externalidades ambientais negativas para o solo, ar e efeito estufa, quando não ocorre o destino adequado dos dejetos da produção. Nesta discussão, os resultados confirmam a importância da avaliação de desempenho da produção suinícola de forma contínua, para além da identificação de métricas e indicadores, avaliar os aspectos negativos do seu desenvolvimento e possibilitar a minimização das externalidades negativas.

Destaca-se que a pesquisa preenche uma lacuna identificada no contexto teórico-prático da mensuração das externalidades (positivas e negativas) das atividades rurais, visando contribuir com a avaliação da sustentabilidade e na minimização das externalidades negativas dos processos produtivos rurais. De forma geral, o estudo não pretende esgotar a discussão sobre os indicadores e as métricas de avaliação para a atividade suinícola, mas sim contribuir com melhorias no processo de avaliação da sustentabilidade da produção suinícola, servindo de modelo para novos estudos e aplicações em novos contextos ou diferentes propriedades rurais. Espera-se contribuir com a possibilidade de evidenciar que a avaliação da sustentabilidade inclui a análise de externalidades, positivas ou negativas, e na busca por alternativas que priorizem a minimização de externalidades negativas, especialmente no contexto ambiental da produção suinícola.

Recomenda-se para novas pesquisas a aplicação deste constructo em entidades rurais com sistemas de produção distintos, visando a comparação dos resultados. Ainda, recomendase aos gestores públicos a busca por alternativas de investimentos, que possam subsidiar a instalação de biodigestores nas entidades rurais, especialmente em entidades rurais com menos de trinta hectares de área útil disponível para destino dos dejetos da produção.

Por fim, acredita-se que o conjunto de indicadores ambientais, sociais e econômicofinanceiros, apresentados pelo SIGEASS, possibilita avaliar a sustentabilidade da produção suinícola, evidenciando às externalidades positivas e negativas do desenvolvimento desta atividade, permitindo a avaliação contínua dos indicadores de desempenhos e a implementação de melhorias em prol da sustentabilidade.

\section{REFERÊNCIAS}

ANGLADE, J. Agriculture durable et écologie: les indicateurs de durabilitè de la IDEA. Mèmorie de maîtrese de biologie dês organismes à L'Université d'Orsay (Paris-Sud XI), 1999.

BAIARDI, D.; MENEGATTI, M. Pigouvian tax, abatement policies and uncertainty on the environment. Journal of Economics, v.103, n.3, p. 221-251, 2011.

BAUMOL, W. J. On taxation and the control of externalities. American Economic Review, p. 62, v.3, p. 307-322, 1972.

BITHAS, K.. Sustainability and externalities: Is the internalization of externalities a sufficient condition for sustainability? Ecological Economics, v.70, p.1703-1706, 2011. 
BRASIL. Lei no 16.342, de 21 de janeiro de 2009. Santa Catarina. Altera e revoga dispositivos da Lei $\mathrm{n}^{\circ}$. 14.675, que institui o Código Estadual do meio ambiente e estabelece outras providências. Disponível em: <https://www.legisweb.com.br/legislacao/?id=264890>. Acesso em: 15 jan. 2017.

BRASIL. Lei $\mathbf{n}^{\mathbf{0}}$ 12.651, de 25 de maio de 2012. Dispõe sobre a proteção da vegetação nativa; altera as Leis $\mathrm{n}^{\mathrm{os}}$ 6.938, de 31 de agosto de 1981, 9.393, de 19 de dezembro de 1996, e 11.428, de 22 de dezembro de 2006; revoga as Leis $\mathrm{n}^{\mathrm{os}}$ 4.771, de 15 de setembro de 1965, e 7.754, de 14 de abril de 1989, e a Medida Provisória no 2.166-67, de 24 de agosto de 2001; e dá outras providências. Disponível em: <http://www.planalto.gov.br/ccivil_03/_Ato20112014/2012/Lei/L12651.htm>. Acesso em: 15 jan. 2017.

BRUNTLAND, G. H. Chairman's foreword. In: UNITED NATONS. Report of the world commission on environment and development. World Commission on Environment and Development (WCED). New York, 1987.

CECHIN, A.; VEIGA, J. E. A economia ecológica e evolucionária de Georgescu-Roegen. Revista de Economia Política, v. 30, n. 3, p. 438-454, 2010.

DAHL, A. L., The big picture: comprehensive approaches. In: MOLDAN, B.; BILHARZ, S. Sustainability indicators: report of the project on indicators of sustainable development. Chichester: John Wiley, 1997.

DALE, V. H.; KLINE, K. L.; KAFFKA, S. R.; LANGEVELD, J.W. A. H. A landscape perspective on sustainability of agricultural systems. Landscape ecology, v. 28, n. 6, p. 11111123, 2013.

DALKEY, N.; HELMER, O. An experimental application of the Delphi method to the use of experts, Management Science, v.9, n.3, p.458-467, 1963.

DELONGE, M. S.; MILES, A.; CARLISLE, L. Investing in the transition to sustainable agriculture. Environmental Science \& Policy, v. 55, p. 266-273, 2016.

DEMING, W. E. Some theory of sampling. Courier Corporation, 1966.

ELKINGTON, J. Canibais com garfo e faca. São Paulo: M. Books, 2012. Título original: Cannibals with forks: the triple bottom line of 21 st century business, Capstone Publishing, 1999.

EMBRAPA. Empresa Brasileira de Pesquisa Agropecuária. Suinocultura e meio ambiente em Santa Catarina: indicadores de desempenho e avaliação sócio-econômica. Concórdia: Embrapa Suínos e Aves, 2009. 201p.

ENSSLIN, L.; GIFFHORN, E.; ENSSLIN, S. R.; PETRI, S. M.; VIANNA, W. B. Avaliação do desempenho de empresas terceirizadas com o uso da metodologia multicritério de apoio à decisão-construtivista. Pesquisa Operacional, v. 30, n. 1, p.125-152, 2010.

ESHET, T., AYALON, O.; SHECHTER, M.. A critical review of economic valuation studies of externalities from incineration and landfilling. Waste Management \& Research, v. 23, n.6, p. 487-504, 2005. 
FARZIN, Y. H.. Optimal pricing of environmental and natural resource use with stock externalities. Journal of Public Economics, v.62, p.31-57, 1996.

FEDERAÇÃO CATARINENSE DE MUNICÍPIOS- FECAM. Sistema de Indicadores de Desenvolvimento Municipal Sustentável. Disponível em:

<https://indicadores.fecam.org.br/banco-indicadores/index/ano/2018>. Acesso em: 03 jun. 2017.

FENG, S. C.; JOUNG, C. B. An overview of a proposed measurement infrastructure for sustainable manufacturing. In: Proceedings of the 7 th Global Conference on Sustainable Manufacturing, Chennai, India. 2009. p. 360.

FIGGE, F.; HAHN, T. Sustainable value added: measuring corporate contributions to sustainability beyond eco-efficiency. Ecological economics, v. 48, n. 2, p. 173-187, 2004.

FRANCO, J. A.; GASPAR, P.; MESIAS, F. J. Economic analysis of scenarios for the sustainability of extensive livestock farming in Spain under the CAP. Ecological Economics, v. 74, p. 120-129, 2012.

HANSEN, J. W. Is agricultural sustainability a useful concept?. Agricultural systems, v. 50, n. 2, p. 117-143, 1996.

HARDI, P.; BARG, S.; HODGE, T. Measuring sustainable development: review of current practices. Occasional Paper, v. 11, p. 49-51, 1997.

HARDI, P.; ZDAN, T. Assessing Sustainable Development: Principles in Practice, Winnipeg: International Institute for Sustainable Development (IISD), 1997.

HENRIQUES, A.; RICHARDSON, J. The Triple Bottom Line: does it all add up? London: Earthscan, 2004.

HUGHES, George. Environmental indicators. Annals of tourism research, v. 29, n. 2, p. 457-477, 2002.

JANNUZZI P. Indicadores Sociais no Brasil: conceitos, fontes de dados e aplicações. Alínea Editora, 2001.

JOHN, A. A.; PECCHENINO, A..International and intergenerational environmental externalities. Scandinavian Journal of Economics, v.99, n.3, p.371-387, 1997.

JOSKOW, P. L.. Weighing environmental externalities: Let's do it right! The Electricity Journal, v. 5, n.4, p. 53-67, 1992.

KAPLOW, L.. Optimal control of externalities in the presence of income taxation. International Economic Review, v. 53, n.2, p. 487-509, 2012.

LINSTONE, H. A.; TUROFF, M. Delphi: A brief look backward and forward. Technological Forecasting and Social Change, v. 78, n. 9, p. 1712-1719, 2011.

MARZALL, K., ALMEIDA, J. Indicadores de sustentabilidade para agroecossistemas: estado da arte, limites e potencialidades de uma nova ferramenta para avaliar o desenvolvimento sustentável. Cadernos de Ciência \& Tecnologia, v.17, n.1, p .41-59, 2000. 
MASOUDI, N.; ZACCOUR, G.. A differential game of international pollution control with evolving environmental costs. Environment and Development Economics, v. 18, n.6, p. 680-700, 2013.

MELNYK, S. A.; BITITCI, U.; PLATTS, K.; TOBIAS, J.; ANDERSEN, B. Is performance measurement and management fit for the future? Management Accounting Research, v. 25, n. 2, p. 173-186, 2014.

MELO, L. E. L. de; CÂNDIDO, G. A. O Uso do método IDEA na avaliação de sustentabilidade da agricultura familiar no município de Ceará-Mirim - RN. Revista de Administração, Contabilidade e Sustentabilidade, v.3, n. 2, p. 1-19, 2013.

MIELE, M. ; WAQUIL, P. D. Cadeia produtiva da carne suína no Brasil. Revista de Política Agrícola, v. 16, p. 75-87, 2007.

NEELY, A. The performance measurement revolution: why now and what next?

International Journal of Operations \& Production Management, v.19, n. 2, p.205-228, 1999.

NORDHAUS, W.. The Economics of The Greenhouse Effect. The Economic Journal, v. 101, n.407, p. 920-937, 1991.

ORGANISATION FOR ECONOMIC CO-OPERATION AND DEVELOPMENT (OECD). An update of the OECD composite leading indicators, 2003. Short-term economic Statistics division, Statistics Directorate/OECD. Disponível em: http://www.oecd.org. Acesso em 08 de ago. 2015.

PARRIS, T.M., KATES, R.W. Characterizing and measuring sustainable development. Annual Review of Environment and Resources, v. 28, p. 559-586, 2003.

PINTÉR, L.; HARDI, P.; MARTINUZZI, A.; HALL, J. Bellagio STAMP: principles for sustainability assessment and measurement. Ecological Indicators, v.17, p.20-28, 2012.

REIG-MARTINEZ, E.; GOMEZ-LIMON, J. A.; PICAZO-TADEO, A. J. Ranking farms with a composite indicator of sustainability, Agricultural Economics, v. 42, n. 5, p. 561-575, 2011.

RIGBY, D.; WOODHOUSE, P.; YOUNG, T.; BURTON, M. Constructing a farm level indicator of sustainable agricultural practice. Ecological economics, v. 39, n. 3, p. 463-478, 2001.

SAEZ, C. A.;REQUENA, J. C.. Reconciling sustainability and discounting in Cost-Benefit Analysis: A methodological proposal. Ecological Economics, v. 60, n.4, p.712-725, 2007.

SANTIAGO-BROWN, I.; METCALFE, A.; JERRAM, C.; COLLINS, C. Sustainability assessment in wine-grape growing in the new world: Economic, environmental, and social indicators for agricultural businesses. Sustainability, v. 7, n. 7, p. 8178-8204, 2015.

SPIES, A. Avaliação de impactos ambientais da suinocultura através da análise do ciclo de vida - ACV. In: Suinocultura e meio ambiente em Santa Catarina: indicadores de desempenho e avaliação sócio-econômica. Org. Miranda, C.R; MIELE, M. Concórdia: Embrapa Suínos e Aves, 2009. 201p. 
TANZIL, D.; BELOFF, B. R. Assessing impacts: Overview on sustainability indicators and metrics. Environmental Quality Management, v. 15, n. 4, p. 41-56, 2006.

VAN BELLEN, H. M. Indicadores de sustentabilidade: uma análise comparativa. FGV Editora, 2005.

VAN DE BERGH, J. C. J. M. Externality or sustainability economics? Ecological Economics, v. 69, n.11, p. 2047-2052, 2010.

VAN PHAM, L.; SMITH, C. Drivers of agricultural sustainability in developing countries: a review. Environment Systems and Decisions, v. 34, n. 2, p. 326-341, 2014.

VELEVA, V.; ELLENBECKER, M. Indicators of sustainable production: framework and methodology. Journal of Cleaner Production, v. 9, n. 6, p. 519-549, 2001.

WEINBERG, M.; KLING, C. L. Uncoordinated agricultural and environmental policy making: An application to irrigated. American Journal of Agricultural Economics, p.78, v.1, p. $65,1996$. 


\section{APÊNDICE A - ROTEIRO ESTRUTURADO UTILIZADO NA CONDUÇÃO DAS ENTREVISTAS COM OS ESPECIALISTAS: ASPECTOS AMBIENTAIS}

Quadro 81: Indicadores de desempenho ambiental (roteiro estruturado)

\begin{tabular}{|c|c|c|c|c|}
\hline $\begin{array}{l}\text { Elementos de } \\
\text { avaliação (32) }\end{array}$ & Indicadores ambientais & $\begin{array}{c}\text { Parâmetro não } \\
\text { recomendável } \\
\text { ou abaixo do } \\
\text { mínimo } \\
\text { aceitável }\end{array}$ & $\begin{array}{l}\text { Parâmetro } \\
\text { aceitável }\end{array}$ & $\begin{array}{l}\text { Parâmetro ideal } \\
\text { /acima do } \\
\text { mínimo } \\
\text { aceitável }\end{array}$ \\
\hline \multirow{4}{*}{ Solo } & Análise físico/químico do solo & & & \\
\hline & Manejo do solo & & & \\
\hline & Ocupação da terra & & & \\
\hline & Área de preservação permanente & & & \\
\hline \multirow{4}{*}{ Àgua } & Origem da fonte utilizada para consumo dos animais & & & \\
\hline & Distância entre instalações das nascentes ou efluentes & & & \\
\hline & Reaproveitamento de águas & & & \\
\hline & Análise físico/químicos dos efluentes & & & \\
\hline \multirow{2}{*}{ Ar /efeito estufa } & $\begin{array}{l}\text { Emissões, Efluentes e Resíduos de gases com efeito } \\
\text { estufa, por peso }\end{array}$ & & & \\
\hline & $\begin{array}{l}\text { Percentagem de dias com ar de má qualidade do ar } \\
\text { como resultado da atividade/produção }\end{array}$ & & & \\
\hline \multirow{3}{*}{ Energia } & Uso total de energia (em kwh) & & & \\
\hline & $\begin{array}{l}\text { Economia de energia devido a melhorias na conservação } \\
\text { e na eficiência (ex. biodigestores) }\end{array}$ & & & \\
\hline & $\begin{array}{l}\text { Consumo direto de energia, discriminado por fonte de } \\
\text { energia primária }\end{array}$ & & & \\
\hline \multirow{7}{*}{$\begin{array}{l}\text { Práticas } \\
\text { ambientais }\end{array}$} & Tratamento de dejetos & & & \\
\hline & Descarte de resíduos sólidos & & & \\
\hline & Limpeza de instalações/ destino dos resíduos líquidos & & & \\
\hline & *Geração/ Produção de dejetos & & & \\
\hline & Distribuição dos dejetos no solo & & & \\
\hline & Descarte de animais & & & \\
\hline & Plano de controle de pragas ( raticidas e inseticidas) & & & \\
\hline \multirow{11}{*}{$\begin{array}{l}\text { Gestão } \\
\text { ambiental }\end{array}$} & Conhece leis e normativas- licenciamento ambiental & & & \\
\hline & $\begin{array}{l}\text { Sanções não monetárias por descumprimento das leis e } \\
\text { regulamentos ambientais }\end{array}$ & & & \\
\hline & Exercício de atividade sem licença ambiental & & & \\
\hline & $\begin{array}{l}\text { Número total de incidentes resultantes da não- } \\
\text { conformidade com os regulamentos ambientais }\end{array}$ & & & \\
\hline & Registros e documentação & & & \\
\hline & Município tem planejamento estratégico & & & \\
\hline & Concorrer para a prática dos crimes previstos em Lei & & & \\
\hline & Passivos ambientais (custos $\mathrm{R} \$$ de capital anual) & & & \\
\hline & $\begin{array}{l}\text { Custos de desempenho econômico atribuíveis a multas } \\
\text { (\% em relação aos custos operacionais) }\end{array}$ & & & \\
\hline & Integrador investe em políticas de gestão ambiental & & & \\
\hline & Ações corretivas e preventivas & & & \\
\hline Outros aspectos & $\begin{array}{l}\text { Outros indicadores sugeridos/propostos pelos } \\
\text { especialistas }\end{array}$ & & & \\
\hline
\end{tabular}

Fonte: Adaptados a partir da literatura pesquisada. 


\section{APÊNDICE B - ROTEIRO ESTRUTURADO PARA APLICAÇÃO DO SIGEASS}

\begin{tabular}{|c|c|}
\hline \multicolumn{2}{|c|}{ Check list 1: Características gerais da propriedade rural que desenvolve atividade suinícola } \\
\hline \multicolumn{2}{|c|}{ Sistema de criação de suínos } \\
\hline Unidade de terminação (UT) & quantidade média de animais \\
\hline Crechário & quantidade média de animais \\
\hline Ciclo completo & quantidade média de animais \\
\hline Unidade de produção de leitões (UPL- 6kgs) & quantidade média de animais \\
\hline Unidade de produção de leitões (UPL- 25kgs) & quantidade média de animais \\
\hline Quantidade média de matrizes & quantidade média de animais \\
\hline Quantidade média de suínos alojados (total) & *média por $\mathrm{m} 2$ \\
\hline Tamanho da propriedade rural - em hectares & $100 \%$ \\
\hline Área utilizada em pastagens & $\%$ \\
\hline Área utilizada em benfeitorias/instalações & $\%$ \\
\hline Área de reserva legal & $\%$ \\
\hline Área de preservação permanente & $\%$ \\
\hline Área utilizada com outras culturas/cultivos & $\%$ \\
\hline Utiliza área cedida ou arrendada para destino de dejetos & (hectares) \\
\hline \multicolumn{2}{|l|}{ Se possui parceria - qual a entidade } \\
\hline \multicolumn{2}{|l|}{ Outras atividades desenvolvidas } \\
\hline Integrantes da família que colaboram na atividade suinícola & pessoas \\
\hline Colaboradores que atuam na atividade suinícola & * Registrados com carteira-CLT \\
\hline Quantidade de terceiros temporários que atuam na atividade & Colaboradores \\
\hline Remuneração média mensal dos colaboradores* & *agregar 13 salário/férias \\
\hline Capacidade das instalações (tamanho em m2) & $\mathrm{m} 2$ \\
\hline Tempo médio dos dejetos nas esterqueiras & *nunca inferior a 40 dias \\
\hline \multicolumn{2}{|l|}{ Valor presente dos investimentos realizados ( $\mathrm{R} \$$ - de instalações físicas) } \\
\hline \multicolumn{2}{|l|}{ Valor médio por lote de suíno entregue (receita bruta) } \\
\hline $\begin{array}{l}\text { Outros custos relativos a atividade (energia elétrica, água, mão de obra } \\
\text { de terceiros }\end{array}$ & * \\
\hline \multicolumn{2}{|c|}{ Análise físico-química do solo (recolha de material para análise laboratorial) } \\
\hline LCA-P (limite crítico ambiental de Fósforo) & $* 40 \%$ cfe IN11/2015 \\
\hline Distribuição dos dejetos (m3 dejetos/ha/ano) & $(\mathrm{m} 3$ dejetos/ha/ano $)$ \\
\hline Distância entre as instalações e fontes naturais & metros \\
\hline Rios/nascentes ou córregos/riachos & metros \\
\hline Açudes & metros \\
\hline Identificação/proximidade de cursos de água & metros \\
\hline \multicolumn{2}{|l|}{ Sistema utilizado para destino dos dejetos } \\
\hline Esterqueira & metros/capacidade \\
\hline Composteira & metros/capacidade \\
\hline Biodigestor & metros/capacidade \\
\hline
\end{tabular}

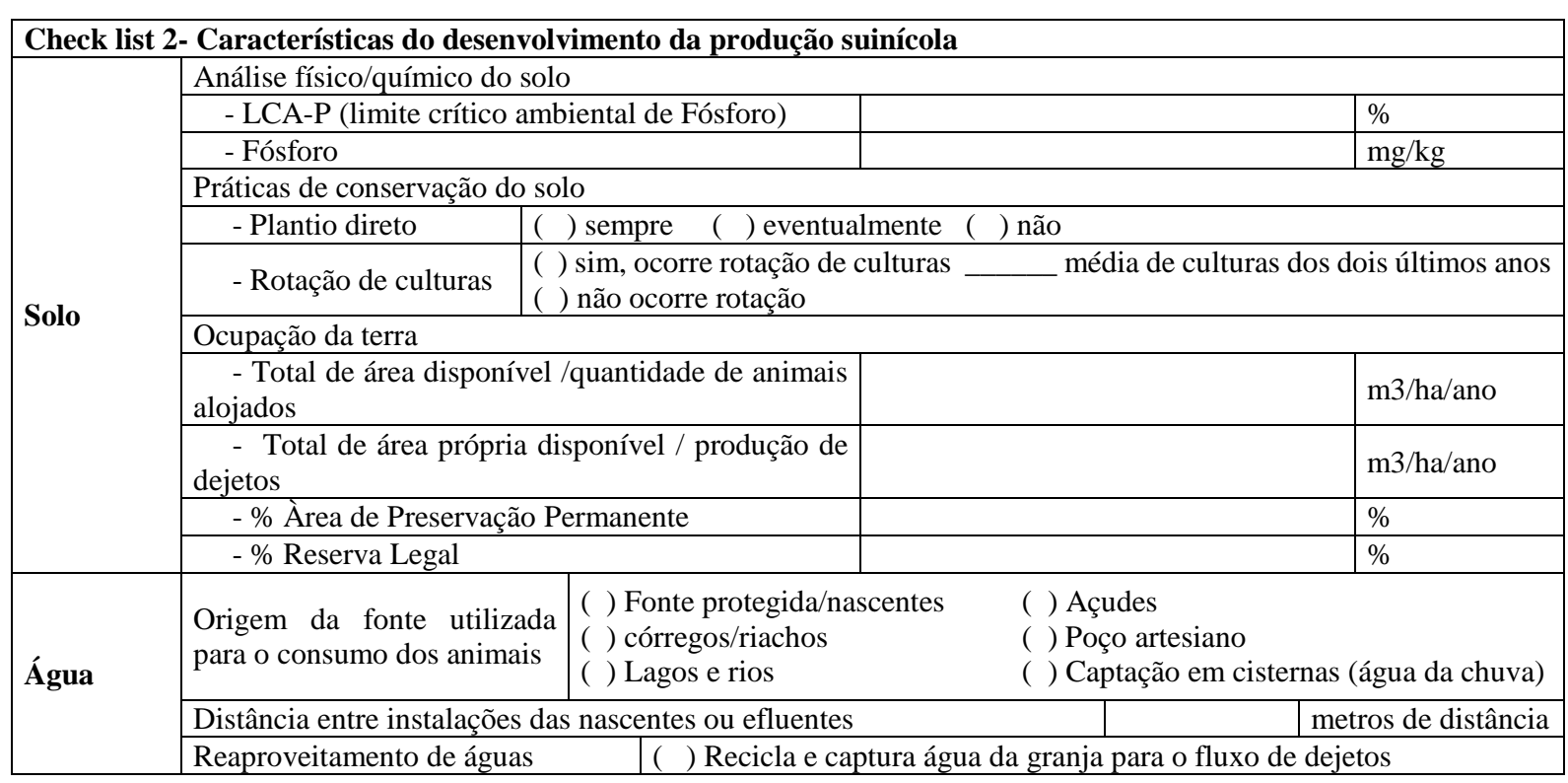




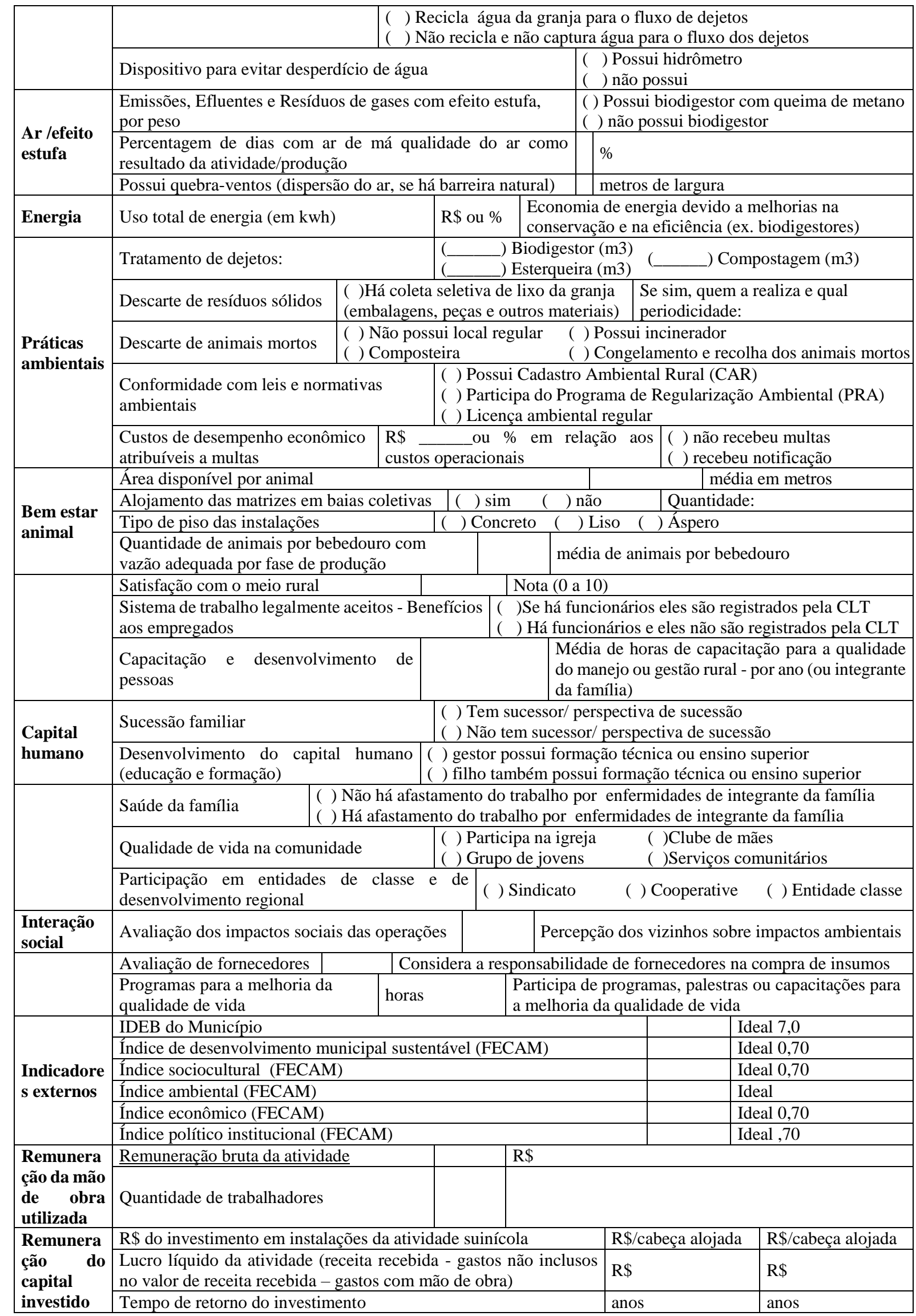

